\title{
Oxidative stress in intensive care unit patients: A review of glutathione linked metabolism and lipid peroxidation
}

\author{
Srikala Meda MD, Sharda P. Singh PhD, Philip T. Palade PhD, Sahil Tonk, Sanjay Awasthi MD
}

\begin{abstract}
Despite clear evidence of increased oxidative stress in the blood and tissues of critically ill intensive care unit patients, consistent beneficial effects of many different antioxidants have not been observed, and antioxidant therapy has not yet translated into widely accepted clinical practice. The reasons for this are unclear, likely rooted in the complex and context dependent free radical behavior of antioxidants interacting with the process of lipid peroxidation. Control of lipid peroxidation is a crucial requirement for the beneficial effects of antioxidants, but the interactions of biological antioxidant defenses with the potentially harmful free radical behavior of pharmacological antioxidants complicates the dose and selection of the optimal antioxidants. Glutathione, the primary small molecule antioxidant in biological systems, is the primary enzymatic oxidative stress defense that operates in the context of glutathione-linked antioxidant enzymes to metabolize many harmful products of lipid peroxidation to mercapturic acids. Recently, the mercapturic acid transporter protein, RLIP76 (human RALBP1 gene), has been shown to have a critical role in glutathione linked oxidative stress defenses. These findings provide a rationale for new approaches towards selection and dosing of antioxidant to improve their clinical benefit.
\end{abstract}

Keywords: Oxidative stress, multiorgan failure, lipid peroxidation, antioxidant, Ralbp1, RLIP76, p53, TP53

\section{INTRODUCTION}

Critically ill patients frequently develop multiorgan failure, with an overall clinical picture consistent with acute decompensation of chronically damaged organs. ${ }^{1,2}$ The precipitating event that leads to intensive care unit admission is often severe injury to one organ system, followed by a domino effect that rapidly and progressively amplifies the initial injury into decompensation and failure of most or all of the major organs. ${ }^{1,2}$ The chain of organ failure most frequently

Corresponding author: Sanjay Awasthi Contact Information: Sanjay.awasthi@ttuhsc.edu DOI: 10.12746/swrccc.v7i27.511 affects the pulmonary, cardiovascular, renal, hepatic, and nervous systems. Overwhelming lung damage from pneumonia leads to hypoxemia and circulatory collapse; massive myocardial infarctions or fatal arrhythmias result in cardiogenic pulmonary edema; liver dysfunction occurs as a result of congestive hepatopathy due to right heart failure; renal failure ensues from reduced renal blood flow due to circulatory collapse; encephalopathy occurs consequent to hypoxemia, uremia, or hepatic failure; insulin resistance and other endocrinopathies accompany any or all of these events. ${ }^{3}$ Not infrequently, therapeutic interventions to treat one failed organ contribute to injury to other organs. Antibiotics to treat infections cause renal failure or hepatic damage; anticoagulants to treat pulmonary embolism or myocardial infarction result in 
gastrointestinal hemorrhages; antiepileptic drugs to treat seizure promote cardiac arrhythmias. ${ }^{4}$

The self-amplifying chain of events of an increasing number of failed organs is in many ways analogous to the self-amplifying free radical chain reactions that underlie oxidative degeneration of biomolecules, collectively referred to as oxidative stress. ${ }^{5,6}$ The concept of oxidative stress underpins the prevailing theories of aging and the mechanisms that lead to age related degenerative diseases. Indeed, evidence of increased oxidative stress can be observed in critically ill patients in the form of one or more markers of oxidative stress. The intensity of oxidative stress is correlated with the severity of illness, number of organs damaged, and likelihood of a fatal outcome..$^{7-9}$

Because oxidative stress has also been identified as a common denominator in the molecular mechanisms that cause chronic and acute cellular and tissue damage that lead to chronic diseases and acute disorders, it would seem logical that interventions that generally reduce oxidative stress should limit its damaging effects. ${ }^{10,11}$ Antioxidant is a general term for any intervention that diminishes oxidative stress. A narrow definition commonly used refers to a wide variety of chemicals, frequently derived from plants and other natural sources, which can inhibit oxidative stress reactions.

Despite this unifying model of oxidative stress as the common pathophysiological mechanism for chronic and acute injuries that contribute to the morbidity and mortality of acutely ill ICU patients, broadly applicable and rational antioxidant strategies to mitigate oxidant-induced damage have yet to be developed. ${ }^{12-14}$ The therapeutic challenge is rooted in the ubiquitous, imprecise, and often erroneous use of the term 'oxidative stress' in scientific and lay literature that obfuscates a nuanced understanding of complex chemical and biological reactions that govern the balance between beneficial (physiological) versus harmful (pathological) effects of oxidative stress. Because antioxidants also exert oxidative effects depending on their chemical structures, concentrations, and the redox milieu, and because of the large number of potential ambient and stress induced redox pairs in biological systems, the prediction of the ultimate beneficial vs. harmful effects after exposure to oxidants or antioxidants is particularly difficult. Our studies of the metabolism of genotoxic compounds by glutathione (GSH), the chief biological antioxidant in cells, have revealed new strategies for identifying beneficial antioxidants and titrating optimal dosing necessary for developing therapies to prevent and/or treat multiorgan failure in ICU patients. ${ }^{12-14}$

\section{Chemical basis of oxidATIVE STRESS}

A general definition of oxidative stress is the increase in electron deficient molecules (oxidants) sufficiently reactive to remove electrons from neighboring molecules (reductants), thereby reducing themselves and oxidizing their neighbors. In biological systems, most frequently, the reactive sites of oxidant (or reductant) molecules contain oxygen, nitrogen, or metal ions that can gain or lose one or two electrons. ${ }^{15-17}$ Oxidative stress is a universal phenomenon that occurs in a controlled fashion in all cells during many physiological events ranging from oxidative phosphorylation to hormone receptor signaling in membranes. Stress, an event that deviates a cell from a homeostatic equilibrium, is nearly universally translated into oxidative stress in the biomolecules comprising cellular organelles, particularly the lipid bilayers. Lipids are particularly susceptible to oxidative stress because they are highly reduced (oxygen deficient) molecules rich in carbon-hydrogen bonds. Indeed, the process of oxidative lipid degradation, lipid peroxidation, has become synonymous with oxidative stress in biological systems. ${ }^{15-17}$

The term lipid peroxidation encompasses a number of reactions in which oxygen reacts with membrane lipids, accompanied by the release of biologically active degradation products, which are used by cells to amplify physiological signals. Most of the same chemical reactions and intermediates are initiated or propagated by oxidative stress, a more intense and damaging form of stress than that involved in physiological signaling. ${ }^{15-17}$ The initiation of biological oxidative stress in the form of the chain reaction of lipid peroxidation requires the formation of highly reactive biological free radicals, defined as molecules containing an unpaired electron in any (usually outermost) orbital. ${ }^{18,19}$ Exogenous oxidative stress amplifies ambient biological oxidative stress through chemical 


\section{Polyunsaturated (Essential) Fatty Acids}

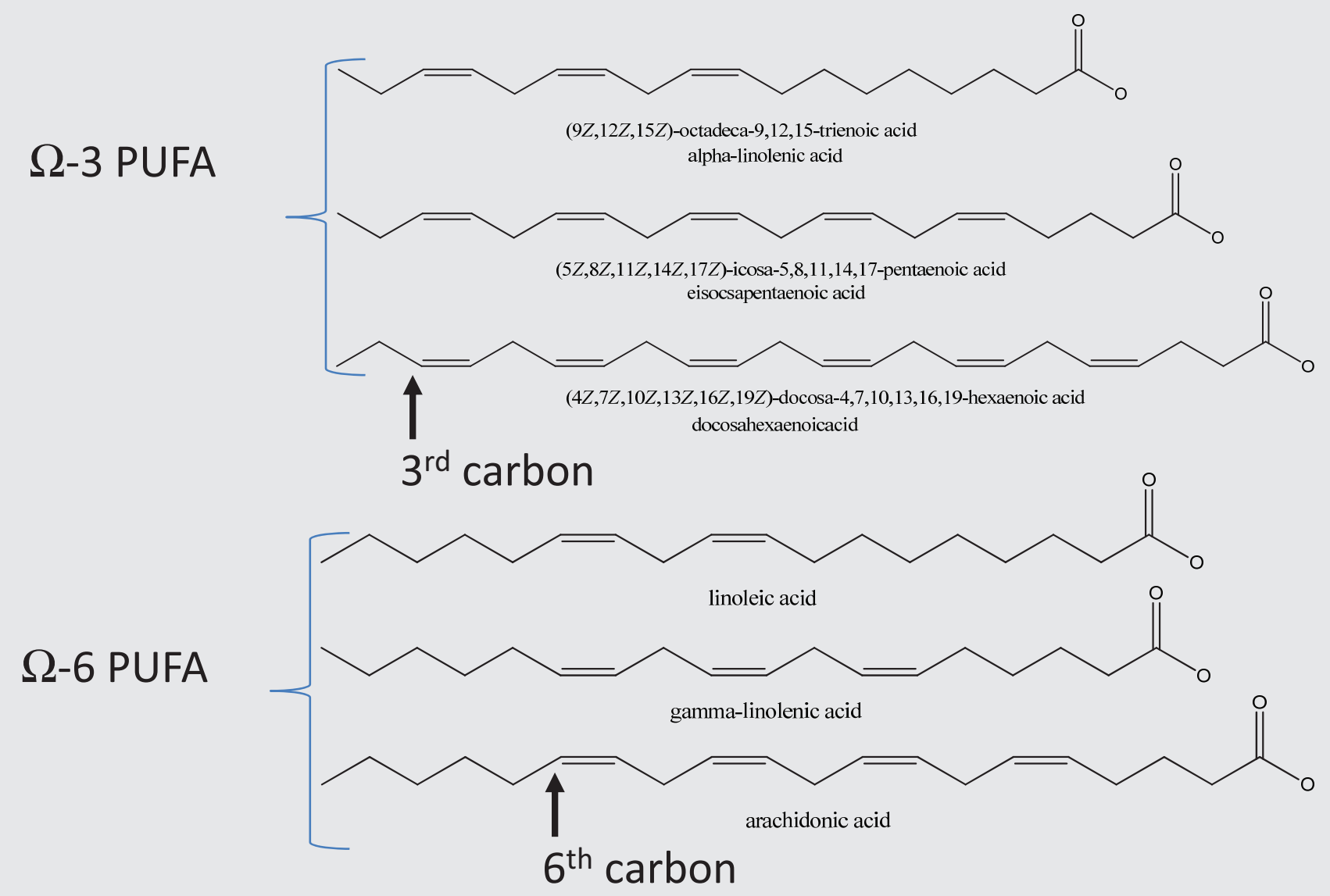

Figure 1. Polyunsaturated fatty acids.

The $\Omega-3$ and $\Omega-6$ designation is based on the location of the first double bond from the end (farthest from the carboxyl group of the fatty acid). The alternating double bonds confer stability due to resonance.

reactions centered on the chain reaction of lipid peroxidation of polyunsaturated fatty acids (PUFA, aka essential fatty acids) (Figure 1). This chain reaction is initiated through formation of oxygen free radicals and propagated by subsequent formation of lipid hydroperoxides (LOOH) ${ }^{16}$ Due to its oxygen rich and PUFA rich environment, the lung is particularly susceptible to oxidative injury, especially when mechanical ventilation with high partial pressures of $\mathrm{O}_{2}$ is necessary, and normal physiological antioxidant defenses are depleted and are unable to scavenge free radicals or metabolize downstream reactive oxygen species (ROS). ${ }^{20-21}$
Initiation of the chain reaction of lipid peroxidation requires the spark provided by the reduction of $\mathrm{Fe}^{+3}$ to $\mathrm{Fe}^{+2}$ using a single electron provided by the $\mathrm{O}_{2}^{-\cdot}$ (superoxide anion radical) formed during oxidative respiration in mitochondria. ${ }^{18,19}$ Because an estimated $1-2 \%$ of all $\mathrm{O}_{2}$ utilized by mitochondria results in formation of $\mathrm{O}_{2}{ }^{-*}$, the higher the partial pressure of $\mathrm{O}_{2}$ and the more active the mitochondria, the greater the production of $\mathrm{O}_{2}{ }^{-*}$ and other highly reactive oxygen free radicals, such as singlet oxygen $\left({ }^{1} \mathrm{O}\right)$. High energy radiation (heat, UV-light and X-rays) generates free radicals directly from water and oxygen without other chemical intermediates. ${ }^{18,19}$ 
Figure 2. Mechanism of lipid peroxidation.

A schematic of showing the reactions that lead to production of lipid hydroperoxides $(\mathrm{LOOH})$ is shown. Free radicals are designated by the dot. Superoxide anion redicals $\left(\mathrm{O}_{2}^{-{ }^{-*}}\right)$ are generated from 1-electron reduction of $\mathrm{O}_{2}$ with the electrons arising from redox reaction in the mitochondria or peroxisomes and from 450 catalyzed mono-oxygenation of xenobiotic compounds, or from the absorption of radiant energy by water. Superoxide dismutase (SOD) acts on $\mathrm{O}_{2}{ }^{-*}$ to generate hydrogen peroxide $\left(\mathrm{H}_{2} \mathrm{O}_{2}\right.$, or $\left.\mathrm{HOOH}\right)$ which is degraded by catalase (CAT). The 1-electron oxidation of $\mathrm{Fe}^{+2}$ to $\mathrm{Fe}^{+3}$ generates the hydroxyl radical $\left(\mathrm{OH}^{\circ}\right)$, which is sufficiently reactive to abstract a single electron from a lipid (L-H) to yield the lipid alkyl radical $(\mathrm{L} \bullet$ ). Because of its stability, LH is most frequently a polyunsaturated fatty acid (PUFA). L combines with $\mathrm{O}_{2}$ to form the lipid-peroxy radical (LOO•) which can abstract a hydrogen atom from a neighboring LH to yield the lipid hydroperoxides $(\mathrm{LOOH})$ and an $\mathrm{L} \bullet$ is regenerated. A 1-electron reduction of LOOH yields a lipoxy radical (LO•), which abstracts a hydrogen from a

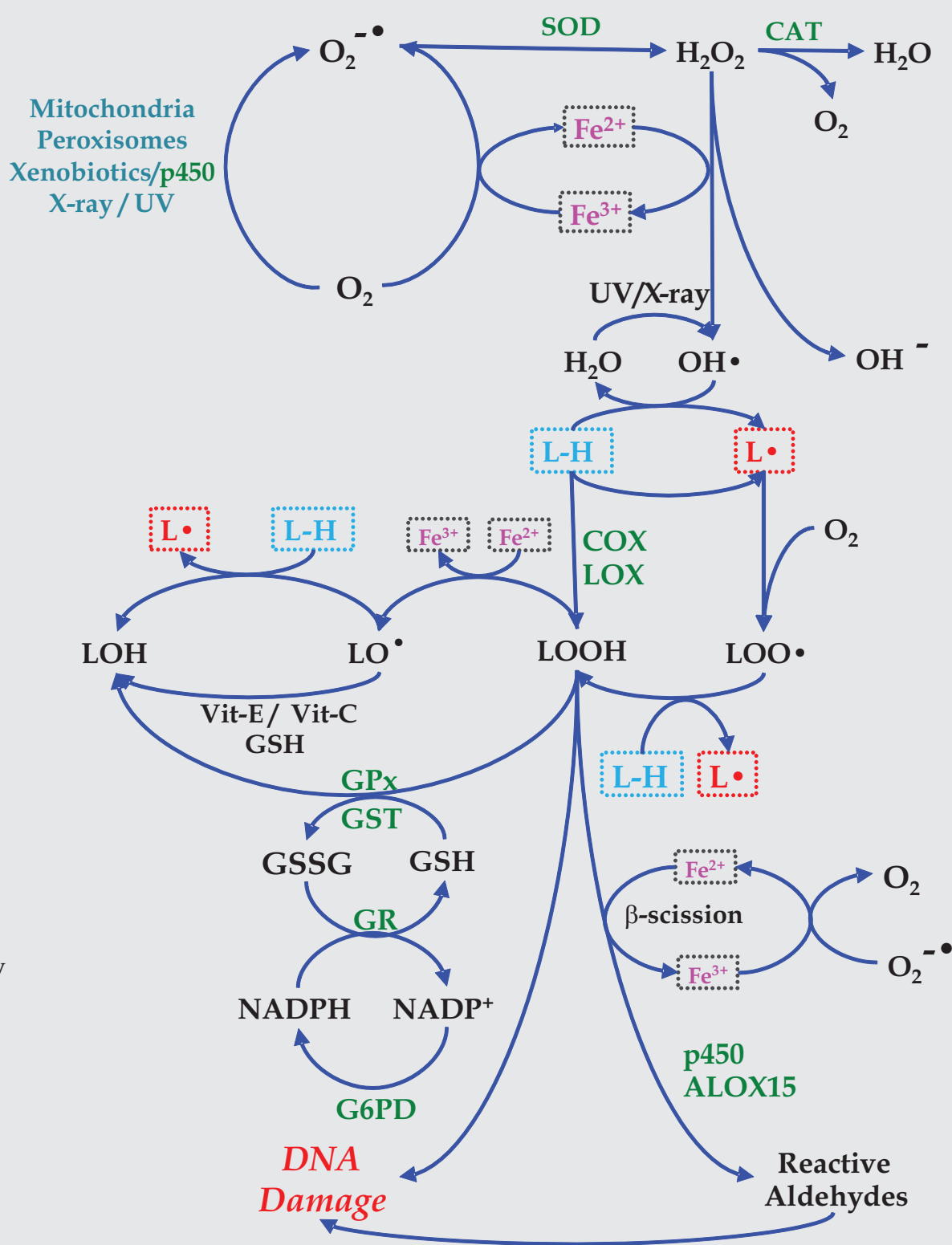
neighboring $\mathrm{LH}$ to yield another $\mathrm{L} \cdot$ and a lipid alcohol ( $\mathrm{LOH})$. This reaction can occur through electron transfers involving vitamin $\mathrm{E} / \mathrm{C}$ and $\mathrm{GSH}$. Alternatively, $\mathrm{LOOH}$ can be directly reduced to $\mathrm{LOH}$ in reaction catalyzed by glutathione S-transferases (GST) or glutathione-peroxidase (GPx). Glutathione (GSH) oxidized to the disulfide (GSSG) is then reduced back to GSH using 2-electrons from NADPH by a reaction catalyzed by glutathione reductase (GR). The $\mathrm{NADP}^{+}$formed as a result is then reduced back to NADPH by glucose-6-phosphate dehydrogenase (G6PD). Thus, one $\mathrm{L} \cdot$ formed by reaction of $\mathrm{LH}$ with $\mathrm{OH} \bullet$ results in a net gain of one $\mathrm{L} \bullet$ for each $\mathrm{LOOH}$ formed, resulting in progressive amplification of lipid peroxidation and consumption of LH. Reactive aldehydes and epoxides form from LOOH through enzymatic and $\mathrm{Fe}$ catalyzed reactions that are fed by electrons from $\mathrm{O}_{2}{ }^{-}$, a reason for the essential importance of the formation of this radical. These are alkylating agents that cause DNA mutations and strand breaks. Physiological formation of $\mathrm{LOOH}$ is catalyzed by cyclooxygenase and lipoxygenase enzymes. 
Excessive caloric intake increases the flux of $\mathrm{O}_{2}$ in mitochondria and damage to mitochondrial membranes caused by oxidant xenobiotics, heavy metals (that have redox properties similar to $\mathrm{Fe}$ ), or high energy radiation increase the 'leakage' of $\mathrm{O}_{2}^{-\cdot}$ from the electron transport chain during oxidative phosphorylation. Similarly, oxidative injury due to increased endogenous or exogenous oxidative stress increases $\mathrm{O}_{2}{ }^{-\bullet}$ leakage during redox reactions in smooth endoplasmic reticulum, peroxisomes, and lysosomes. ${ }^{18,19}$ Xenobiotic compounds containing quinone groups (i.e., doxorubicin, paraquat) can generate large amounts of $\mathrm{O}_{2}^{-*}$ during their metabolism by the cytochrome p450 enzymes. ${ }^{22}$ Oxidative destruction of phagocytosed bacteria and the formation of many otherwise unmetabolizable endogenously produced compounds (i.e., phospholipids) occur in lysosomes and peroxisomes through processes that generate $\mathrm{H}_{2} \mathrm{O}_{2}$ and other ROS; the resultant membrane damage to these vesicles increased by exogenous oxidative stress allows the escape of ROS. ${ }^{20,21}$

Radiant or chemical oxidative stress amplifies physiological production of superoxide anion radical $\left(\mathrm{O}_{2}^{-*}\right)$ through 1-electron reduction of $\mathrm{O}_{2}$ by electrons from the mitochondrial or vesicular electron transport chains. In humans, this leak is the major physiological source ROS, the defining characteristic of oxidative stress (Figure 2). The mitochondrial metalloenzyme, manganese superoxide dismutase (Mn-SOD), converts $\mathrm{O}_{2}^{-\cdot}$ to $\mathrm{O}_{2}$ and $\mathrm{H}_{2} \mathrm{O}_{2}$. An increase in $\mathrm{O}_{2}^{-\cdot}$ due to radiant or chemical oxidative stress promotes the Fenton reaction, oxidation of $\mathrm{H}_{2} \mathrm{O}_{2}$ by $\mathrm{Fe}^{+3}$ to yield the hydroxyl radical $(\mathrm{OH} \bullet)$ and $\mathrm{Fe}^{+2}$. $\mathrm{OH} \bullet$ is sufficiently electronegative to pull a single electron from a membrane lipid fatty acid chain (LH), typically an $\omega-3$ or $\omega-6$ polyunsaturated fatty acid (PUFA). ${ }^{18,19}$ The resultant short-lived free radical lipid ( $\mathrm{L} \cdot$, alkyl-radical) binds $\mathrm{O}_{2}$ to form the lipid peroxy radical (LOO•), which becomes a lipid hydroperoxide $(\mathrm{LOOH})$ by directly or indirectly pulling off an electron from an adjacent lipid, regenerating $L \cdot$. In an iron rich environment, $\mathrm{Fe}^{+3}$ causes a single electron oxidation of $\mathrm{LOOH}$ to yield LO• (alkoxy radical), which can subsequently generate another $L \cdot$ by abstracting a hydrogen from and adjacent lipid: one lipid free radical generates two, the basis of an ever- amplifying chain reaction. ${ }^{16}$ Presented in a simplified form here, lipid peroxidation is a highly complex and not fully understood process that involves formation of numerous transient oxo-lipid intermediates containing 1,2 or 3 oxygen atoms. ${ }^{18,19}$ Their formation, thus the composition of lipid peroxidation products, is highly dependent on numerous environmental variables, such as $\mathrm{pO}_{2}$, temperature, $\mathrm{pH}$, the concentration of mono and divalent cations or anions, membrane concentration of free radical scavengers and biological antioxidant enzymes, cholesterol concentration, the type of phospholipids, and the type and concentration of PUFA. ${ }^{16}$

Phosphatidyl inositol $(\mathrm{PI})$ is a phospholipid present at low concentrations in eukaryotic cell membranes, consisting of a phosphoinositol head group esterified through glyceryl hydroxyl groups to two fatty acid chains, such as the PUFA (Figure 3 ). It is the source of numerous bioactive lipid second messengers in inflammation and oxidative stress. Phosphatidyl inositol is the substrate for hydrolases, kinases, and lipoxygenases; it is metabolized to numerous small molecule second messengers. ${ }^{18,19}$ The second messengers arising from PI can be divided into: 1) phosphatidylinositolphosphates (PIPs) formed from sequential phosphorylation of the hydroxyl group of the inositol moiety of intact $\mathrm{PI}$; 2) inositol phosphates (IPs) formed from sequential phosphorylation of the inositol phosphate after phospholipase $C$ cleaves off the diacylglycerol (DAG) group; and 3) PUFA-hydroperoxides after their hydrolysis from DAG by phospholipase A2 (PLA2). ${ }^{18,19}$

Phosphatidyl inositol kinases (PIKs 3, 4 and 5) sequentially phosphorylate the hydroxyl groups on the inositol moiety of PI yielding the phosphatidylinositol triphosphate ( $\mathrm{PI}[3,4,5] \mathrm{P})$, which activates proteinkinase B (AKT). The phosphatidylinositol phosphatase, PTEN, dephosphorylates the PIPs, opposing the effects of the PIKs. ${ }^{23}$ The phosphatidylinositol monophosphate PI(3)P activates the small G-proteins RAL, RAC and $\mathrm{RHO}$, which regulate endocytosis and proteintyrosine kinase 2 (PTK2) that regulates cell movement. Phospholipase C (PLC) hydrolyzes PIs to DAGs and IPs. IP-kinases (IPKs) add additional phosphates to inositol phosphate, yielding multiple Pls that activate calmodulin (CALM) to trigger calcium release from endoplasmic reticulum. Calmodulin and $\mathrm{Ca}^{++}$together activate protein kinase C (PKC), which activates inflammation. Inositol phosphates regulate many antioxidant responses, while PKC activates inflammatory pathways. ${ }^{23}$ 


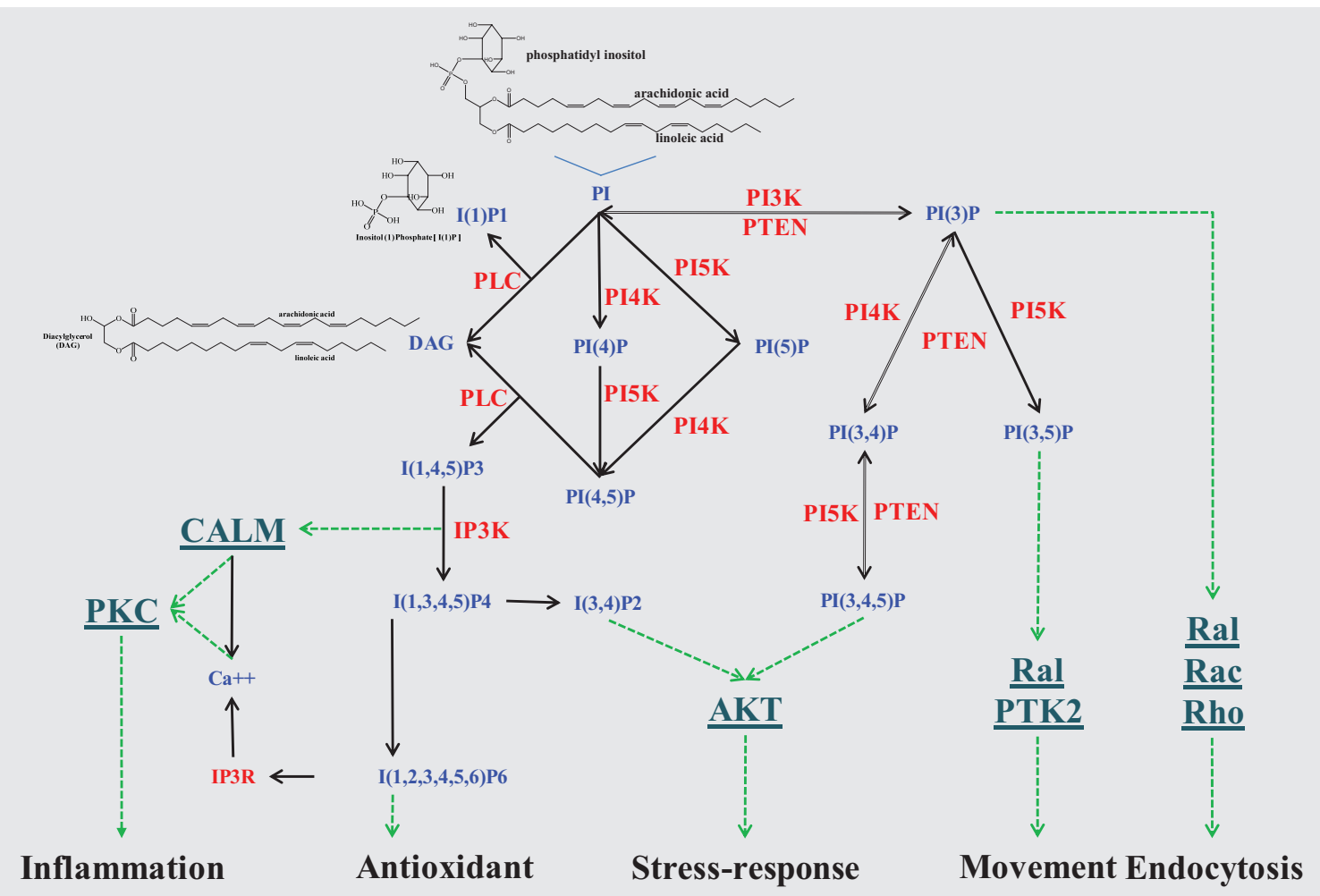

Figure 3. Signaling to kinase pathways down-stream of PUFA-phosphatidyl inositol.

The phosphatidyl inositol kinases (PIK3, PIK4, PIK5) directly phosphorylate PI to yield mono, di and tri-phosphorylatedphosphoinositide (the number in the parenthesis indicates the position of phosphorylation on the inositol moiety). The phosphatase PTEN catalyzes the removal of the phosphate group from PI(3)P. The multiple phosphoinositides that result can activate key signaling proteins, including RAL, RAC, RHO, FADK, AKT, PKC and calmodulin (CALM), that signal downstream events in the pathways of inflammation, antioxidant responses, stress responses, cell movement (cancer-cell invasion), and endocytosis.

In membranes, PUFAs are esterified not only to phosphatidylinositol but also to other phospholipids, including phosphatidylethanolamine, phosphatidylcholine, phosphatidylserine, and sphingolipids. Thus, free PUFA can arise from any of these phospholipids by phospholipase A2 (PLA2) catalyzed hydrolysis (Figure 4, Figure 5). Enzymatic peroxidation of PUFA to cyclic endoperoxides by cyclooxygenases (COX1 and COX2) leads to the formation of thromboxanes and prostaglandins (PG). ${ }^{24}$ Each of these PUFA metabolites binds to specific heterotrimeric G-protein coupled receptors (GPCR) that regulate downstream kinases that have pro- or anti-inflammatory actions. The thromboxanes, derived from cyclic peroxidation, promote tissue damage through their thrombogenic effects. Prostaglandins E2 can exert context dependent pro- or anti-inflammatory effects. Prostaglandins D2 and PGJ2 exert primarily anti-inflammatory effects. 6- keto-PGF $\alpha$ may effect anti-inflammatory effects by inhibiting platelet activation. In contrast, the serum levels of PGF $2 \alpha$ are a confirmed biomarker of oxidative stress. ${ }^{18,19,23,24}$ Both thromboxanes and prostaglandins undergo conjugation with GSH followed by metabolism to mercapturic acids. Lipoxygenase (LOX) or p450 enzymes catalyze the formation of linear hydroperoxides that are converted by several different enzymes to leukotrienes (LT), lipoxins (LP), hepoxilins (HP), hydroperoxyeicosatrienes (HPETE), 4-hydroxynonenal (4-HNE) 


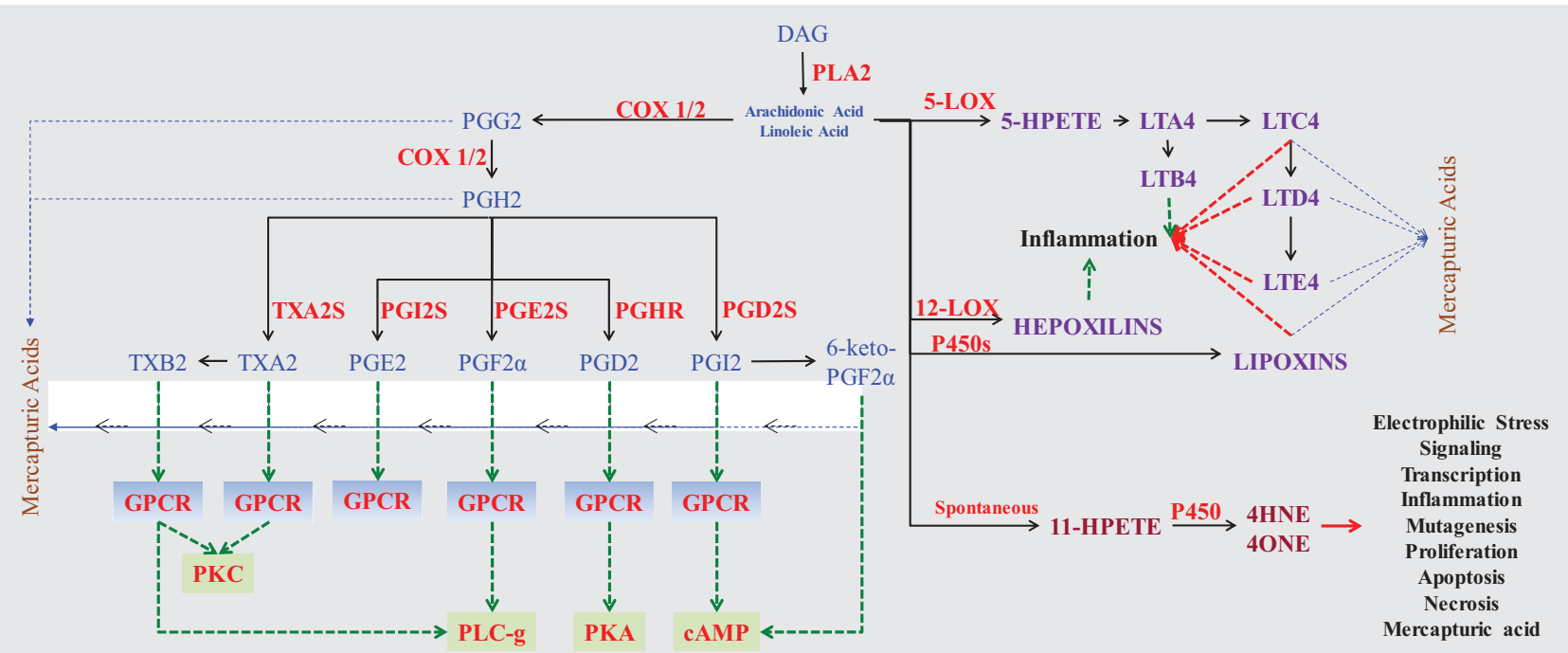

Figure 4. Signaling to GPCRs by products of PUFA peroxidation.

Diacylglycerol (DAG) formed from hydrolysis of PIs (see Fig. 3) are hydrolyzed further by phospholipase A2 (PA2) to free PUFA (i.e. arachidonic and linoleic acid). These PUFA undergo either cyclic or linear peroxidation. Cyclic peroxidation of PUFA by cyclooxygenases $(\mathrm{COX} 1 / 2)$ yields sequentially prostaglandin $\mathrm{G} 2$ and $\mathrm{PGH} 2$. PGH2 is converted to the thromboxanes (TXA2, TXB2) or prostaglandins D2, E2, F2 $\alpha$, 6-keto-F2 $\alpha$, and I2. Each of these binds specific G-protein coupled membrane receptors (GPCRs) to initiate signaling to PKA, PKC, PLC $\gamma$ and cAMP. Prostaglandins as well as thromboxanes are metabolized further to GSH-adducts, which subsequently are converted to mercapturic acids. Linear peroxidation is catalyzed by either 5-lipoxygenase (5-LOX), 12-LOX, or the cytochromes p450 (P450s). The product of 5-LOX catalysis is 5-hydroperoxyeicosatrienoic acid (5-HEPTE). It is the precursor of LTA4 (leukotriene A4, a reactive epoxide), which is glutathionylated by LTC4 synthase (a microsomal glutathione S-transferase) to LTC4 (a pro-inflammatory lipid). Alternatively, the epoxide group of LTA4 is reduced to an alcohol, forming LTB4 (an anti-inflammatory lipid). LTC4 is transported out of cells by mercapturic acid transporters such as Rlip or multidrug resistance associated protein (MRP). Subsequently, extracellular LTC4 is metabolized sequentially by enzymes of the mercapturic acid pathway: LTC4 is converted to LTD4 (by GGT-catalyzed deglutamylation), LTD4 is converted to LTE4 (by dipeptidase-catalyzed removal of glycine), and LTE4 is converted a mercapturic acid (by $\mathrm{N}$-acetyl transferase-catalyzed oxidation) in the kidneys. The 12-LOX catalyzed reaction yields anti-inflammatory hepoxilins. The p450 catalyzed linear peroxidation yield pro-inflammatory lipoxinis (see structures, Figure 5). PUFAs can also undergo spontaneous (non-enzyme catalyzed) reactions to form 11- hydroperoxyeicosatrienes (11-HPETE) that degrade by spontaneous or p450 catalyzed reaction to 4-hydroxynonenal or 4-oxoenal (4HNE or 4ONE). Quantitatively, over $50 \%$ of PUFA peroxidation yields $4 \mathrm{HNE}$ or $4 \mathrm{ONE}$.

and 4-oxononenal (4-ONE). Leukotrienes $\mathrm{C} 4$ is an important physiological pro-inflammatory molecule generated from linear peroxidation of PUFA by LOX. Leukotrienes C4 is a chief component of the 'slow-reacting substance of anaphylaxis' (SRSA) and is a potent endothelial toxin that induces venoconstriction, arteriolar dilation, and leukocyte chemotaxis to sites of inflammation. The linear peroxidation derived hepoxilins are pro-inflammatory, whereas lipoxins inhibit inflammation. ${ }^{18,19,23,24}$

A fine balance in the ratio of these oxidized lipid metabolites regulates inflammation, and excess free radicals and $\mathrm{LOOH}$ generation caused by oxidative stress can amplify these signals, activating inflammation 
<smiles>CCCCC[C@@H](/C=C/[C@@H]1[C@H](C/C=C\CCCC(=O)O)C2C[C@H]1OO2)CO</smiles>

Prostaglandin G2
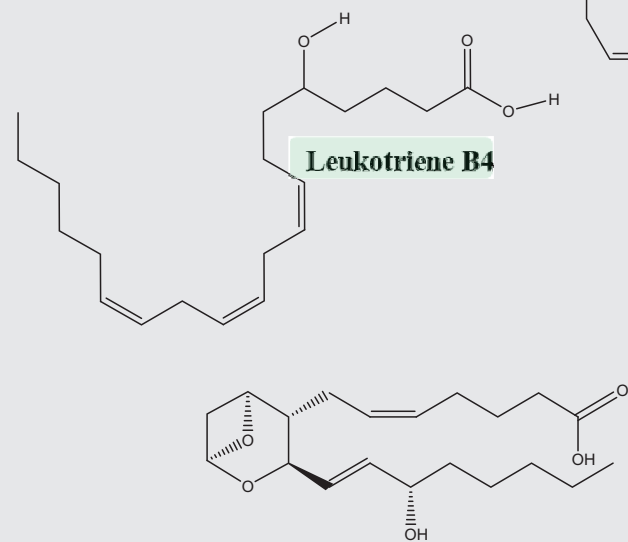

Thromboxane A2

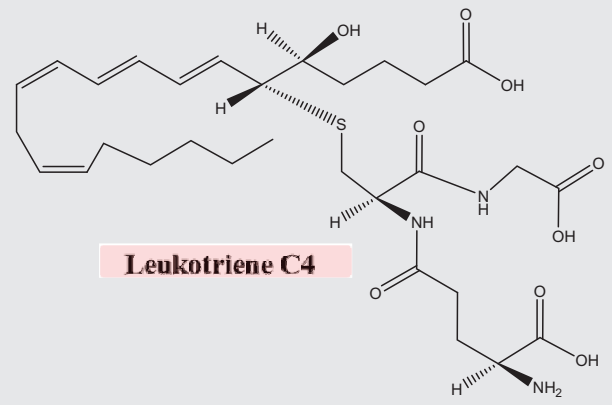

11-hydroperoxy eicosatrienoic acid

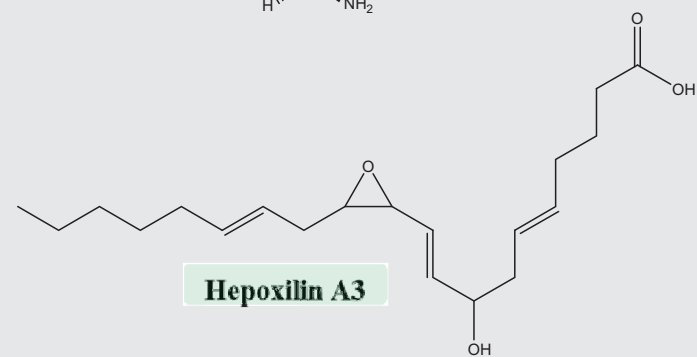

Figure 5. Structures of selected bioactive metabolites of PUFA.

These are derived from peroxidation of PUFA through pathways shown in Figure 4. Red shading indicates proinflammatory actions and green shading indicates anti-inflammatory actions.

and promoting cell damage. ${ }^{15-17}$ Supraphysiological levels of $\mathrm{LOOH}$ induce DNA strand breaks and undergo degradation to mutagenic alkylating compounds, such as epoxides and $\alpha$, $\beta$-unsaturated carbonyls generated from cleavage of the terminal carbons of PUFA (essential fatty acids) through free radical or enzyme catalyzed reaction. 4-hydroxynonenal (4HNE) is the predominant $\alpha, \beta$-unsaturated carbonyl derived from $\omega$-6-PUFA, whereas $\omega$-3-PUFA generates 4-hydroxyhexenal (4HHE); pro- vs. anti-atherogenic potential of $\omega$-6-PUFA vs. $\omega-3-P U F A$ has been attributed to the differential effects of $4 \mathrm{HNE}$ vs. $4 \mathrm{HHE} .{ }^{15-17}$ 4-hydroxynonenal alkylates numerous cellular constituents, including DNA and a large number of signaling kinases, essentially functioning as a universal regulator of responses to oxidative stress. ${ }^{15-17}$
The low ambient concentrations of 4HNE generated during physiological signaling downstream of lipoxygenases act as growth and proliferation signals. Because 4HNE can form through non-enzymatic degradation of lipid hydroperoxides, oxidative stress disproportionately increases its formation. ${ }^{15-17}$ At higher concentration produced by oxidative stress, 4HNE activates stress activated protein kinases (MAPKs, SAPKs), such as Jun-kinase, to trigger oxidative stress defenses through the AP2 (FOS/JUN heterodimer), NRF2, NFkB, and p53. By binding to DNA at the transcription factor binding site, $4 \mathrm{HNE}$ can directly regulate the transcription of stress-, inflammation-, and immune-responsive genes. The proteins encoded by these genes include many cytokines that promote (TNF $\alpha$, IL1, IL2, IL6), inhibit (IL8, IL10), or otherwise 
modulate inflammation (IL6). Inflammatory cytokines promote infiltration of neutrophils, macrophages and lymphocytes that further increase oxidative stress due to active exocytic, phagocytic, peroxisomal, and lysosomal functions. ${ }^{15-19,23,24}$ Because cytokine signaling also increases $\mathrm{LOOH}$ production, it exacerbates the self-propagating reactions that cause tissue necrosis upon exposure to stress of sufficient intensity. By binding to the AP2 transcription factor binding site on DNA, $4 \mathrm{HNE}$ also regulates the transcription and activity of p53, a stress-responsive tumor suppressor protein. Oxidative stress activates $p 53$, resulting in activation of stress defenses, cell cycle arrest to allow DNA repair, and triggering of apoptosis if irreparable damage has occurred. At very high concentrations generated by lethal chemical or X-ray exposure and multi-organ failure in ICU patients, 4HNE alkylates nearly all cellular components and causes tissue necrosis. ${ }^{18,19,23,24}$

\section{Antioxidants}

Lipid peroxidation in response to signaling or stress is subject to many modulators that can accelerate or dampen the process. Any redox process that prevents $\mathrm{LOOH}$ formation or metabolizes $\mathrm{LOOH}$ can terminate the chain reaction of reactive oxygen radicals. Any biological or exogenous biological molecule that terminates lipid peroxidation is an antioxidant. ${ }^{15-17}$ Free radicals can pull off a single electron from neighboring non-radical compounds to achieve a stable non-radical electronic configuration; however, the neighbor that gives up the electron is now a radical itself: thus the principle, free radicals beget free radicals. ${ }^{25}$ This itself is not dangerous because the number of free radicals does not increase - no amplification; a chain reaction requires that one free radical give rise to at least two. This requires a source of single electrons, generally provided in biological systems by metal ions that undergo 1-electron redox (i.e., $\mathrm{Fe}, \mathrm{Cu}, \mathrm{Ni}, \mathrm{Se}, \mathrm{Mn}$ etc.) or high-energy radiation (x-ray, ultraviolet) that can strip off electrons from water to generate oxygen free radicals (ROS) ${ }^{26}$ If the electron from one free radical is accepted by another free radical, both radicals are 'quenched' such that the orbitals of both chemical species contain a pair of electrons. Alternatively, if a reactive free radical donates its electron to non-free radical compound which can form a 'stable' free radical, one that is resonance stabilized by alternating double-bonds, the more reactive radical is quenched, effectively terminating the free radical reaction. ${ }^{25,26}$ Compounds that form stable free radicals exert antioxidant effects. The free radical forms of these antioxidants vary considerably in stability, an underlying reason for the truism that all antioxidants are also oxidants. The less stable an 'antioxidant' free radical is, the more likely it is to transfer its electron to another molecule, which may chemically rearrange to yield an even more reactive/ damaging chemical. The most effective antioxidants are those required at exceedingly low concentration to protect the peroxidation of an 'oxidizable substrate' (i.e., biological membranes, fat, butter, other foods) in which they are dissolved. This is the measuring stick according to which food preservatives/additives are judged - the best ones being those that can prevent rancidity (the characteristic smell of lipid hydroperoxides) at exceedingly low (parts-per-billion) concentrations.

Because heavy metals are an important source of unpaired electrons in biological systems, the most important biological antioxidants are those that sequester heavy metal ions, such as iron, that serve to initiate the lipid-peroxidation reaction through formation of $\mathrm{OH} \bullet$. Metal ion binding proteins, such as ferritin, transferrin, and ceruloplasmin, or chemicals (such as chelating agents) that lower the concentration of unbound heavy metals are excellent antioxidants. ${ }^{27}$ Medical conditions in which heavy metal ion excess promotes oxidative stress include iron overload (hemochromatosis or hemosiderosis), copper overload (Wilson's disease), and heavy metal poisoning ( $\mathrm{Hg}, \mathrm{Pb}, \mathrm{Ni}$, Se, etc.). Chelation therapy can reduce oxidative stress levels in these conditions. ${ }^{28}$

Free radical scavenging (chain-terminating) antioxidants, such as vitamin $E$, vitamin $C$, vitamin $A 3$, vitamin $\mathrm{K}$, vitamin $\mathrm{D}$, uric acid, estrogen, curcuminoids, bioflavonoids, carotenoids, hydroxycinnamates, etc., are chemicals with large resonance stabilized electron clouds; they can 'quench' free radicals that are more reactive by accepting unpaired electrons from the more reactive free radicals. ${ }^{29,30}$ Vitamin $E$ is the most stable free radical in biological systems, more 
stable and potent than any other naturally occurring antioxidant. Natural sources of vitamin E (nearly all oils) contain a large number of isomers of vitamin $E$ that differ slightly in their electron affinity, thus affecting the stability of their free radical state. ${ }^{31,32}$ These isomers essentially create a ladder along which highenergy electrons can descend through small steps that are less likely to cause the damage caused by large changes in their energy states. The same principle applies to many other naturally occurring antioxidants, which are found as mixtures of multiple isomers with slightly different 1 -electron reduction potential (the ease with which they can accept a single electron). Radicals with higher 1-electron reduction potentials will donate electrons to those with lower values. This is important because artificial mixtures of vitamin $\mathrm{E}$ (or other natural antioxidants) lacking the entire natural spectrum of isomers are less effective antioxidants and could indeed promote free radical behavior at high concentrations. ${ }^{33-35}$ Thus, variable physiological levels of vitamin $E$ and its isomers among patients would confound the effects of antioxidant intervention, perhaps the crucial reason why exogenous antioxidants have failed to show efficacy in many clinical trials ${ }^{33-35}$ Presumably, exogenous antioxidants would benefit patients with vitamin E deficiency but not patients sufficient in this vitamin.

Other vitamins with antioxidant activity include biotin, vitamins $A, D$ and $K$, and most important, vitamin C (ascorbate). Vitamin C functions to recycle vita$\min E$ and an inappropriate ratio of vitamins $E$ to $C$ can significantly reduce the efficacy of this free radical scavenging mechanism in limiting damage from lipid peroxidation (Figure 6). Though an ideal concentration of vitamin $C$ is beneficial, an excess could potentially be harmful to a patient with severe iron overload (thus a strong predisposition to oxidative stress) because reactions of vitamin $C$ with iron can generate potent ROS. Unfortunately, the 'ideal' concentration of vitamin $C$ is not known and it may differ among patients. ${ }^{36,37}$ Ultimately, vitamin $\mathrm{C}$ requires $\mathrm{GSH}$ for its regeneration, and GSH concentrations depend on several factors, particularly the intake of the essential sulfur containing amino acid methionine..$^{36,37}$

Antioxidants are abundant in nature, and those derived from plants are referred to as phytoantioxidants.
The majority are phenols with highly variable structures formed from condensation of terpenes in plants. Because their chemical structure allows effective delocalization of unpaired electrons to stabilize the free radical, they exhibit natural antioxidant behavior; very low concentrations of these phytoantioxidants can protect the oxidation of much larger amounts of substrates in which they are dissolved. At very low (nanomolar) concentrations, a phytoantioxidant derived from curcumin and turmeric (aka FDA yellow), delays rancidity (peroxidation) of fats in foods. ${ }^{38,39}$ Phenolic compounds from numerous other plants or fruits display similar activity (Figure 7). Interestingly, the majority of these compounds are found in abundance in spices, the pleasant smell attributable to their aldehyde groups. Thus, in addition to flavor, spices serve as natural preservatives that can not only preserve food but a person as well. Their 1-electron reduction potentials (stability) is highly dependent upon the substrate in which they are dissolved, $\mathrm{pH}$, temperature, type of free radical and many other chemical factors, such that a given compound could act as an effective antioxidant in one setting, and a potent oxidant under another. ${ }^{34,40-42}$ In ex vivo assays, tocopheryl radicals are more stable than the majority of other phytoantioxidants. In such assays, curcumin (a constituent of the spice turmeric) is superior to vitamin $\mathrm{E}$. Unfortunately, ex vivo measurements may be poor surrogates for in vivo biological antioxidant functions, and the best combinations remain unknown. ${ }^{34,40-42}$

Beyond their free radical scavenging activities, phenolic antioxidants also function through activation of biological antioxidant defenses, such as GSH-linked enzymes. ${ }^{43,44}$ Indeed, one of the best indicators of the cancer preventative activity of a putative antioxidant compound is its ability to induce glutathione-linked enzymes. Common food preservatives, such as BHA (butylated hydroxyanisole) or BHT (butylated hydroxytoluene), induce GSTs when administered to rodents, and this induction results in reduced susceptibility to oxidative stress and carcinogenic effects of subsequent carcinogen exposure. ${ }^{30}$

\section{Oxidative stress In ICU PATIENTS}

Critical care admissions often involve acute multiorgan failure superimposed on damage due to 


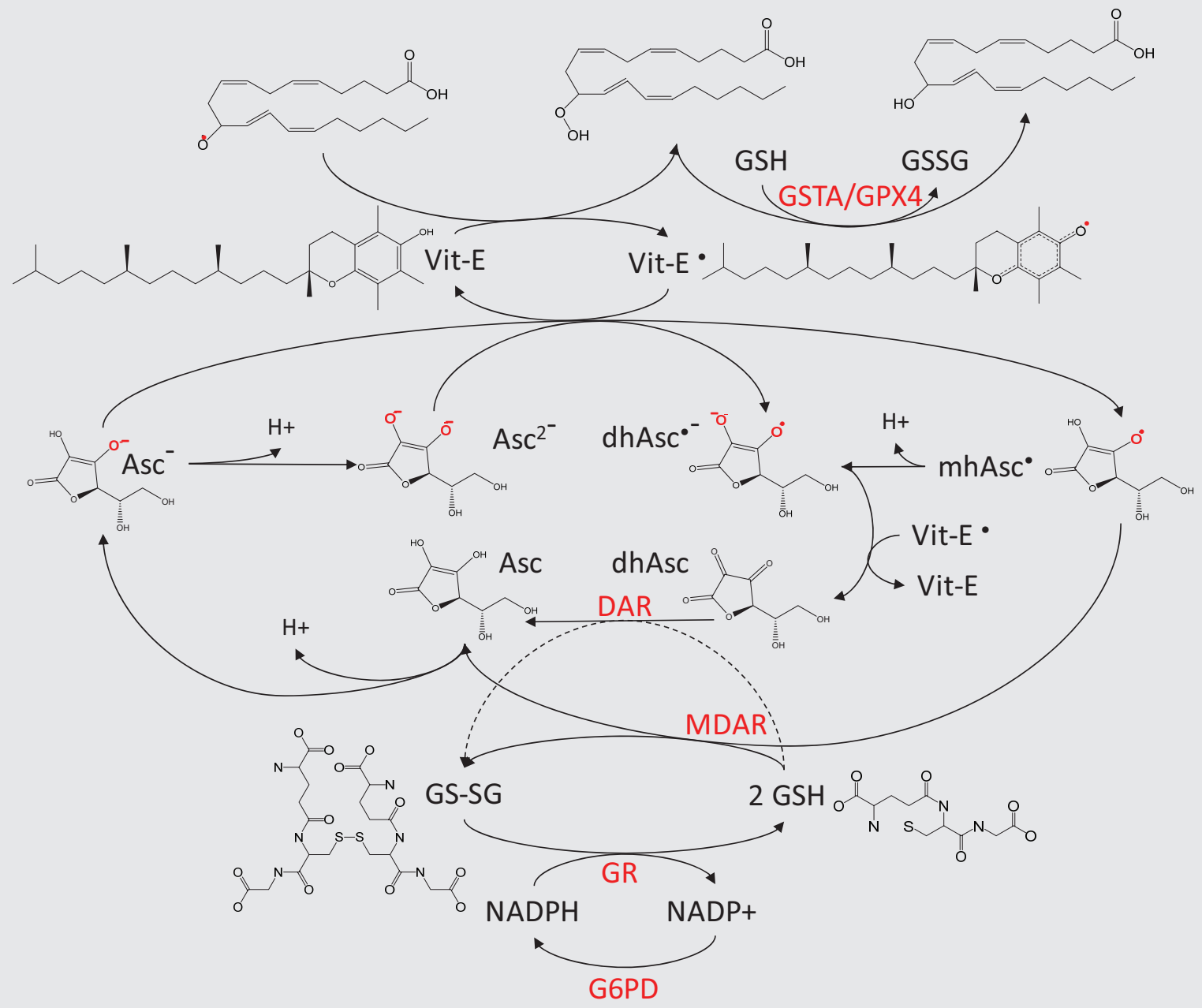

Figure 6. Mechanism of lipid peroxy radical scavenging through concerted actions of vitamin $\mathrm{E}$, vitamin $\mathrm{C}$ and glutathione.

The lipid peroxy radical (LOO•) abstracts a hydrogen atom (1 proton and 1 electron) from tocopherol (vitamin E) resulting in formation of the lipid hydroperoxides $(\mathrm{LOOH})$ and a vitamin $\mathrm{E}$ radical (Vit-E •) which is resonance stabilized by the $\pi$-electrons of the alternating double bonds in vitamin $\mathrm{E}$. Ascorbic acid loses $\mathrm{H}+$ to form mono and di-anionic ascorbates that donate 1 electron to the Vit-E $\bullet$, regenerating Vit-E and forming monodehydro-and dehydroascorbyl radicals ( $\mathrm{dhAsc} \bullet-$ and $\mathrm{mdhAsc} \bullet$ ) which are regenerated by reductions catalyzed by dehydroascorbate and monodehydroascorbate reductase enzymes (DAR and MDAR). The reducing equivalents are from the oxidation of 2 GSH molecules to one GS-SG (oxidized glutathione-disulfide). Glutathione reductase (GR) regenerates GSH from GS-SG using a pair of electrons donated by NADPH. NADP+ that results is restored to NADPH by G6PD using reducing equivalents from oxidation of G6P. Glutathione S-transferase A (GSTA) or glutathione peroxidase 4 (GPX4) reduce the $\mathrm{LOOH}$ to lipid alcohols that cannot participate in further redox cycling. 
<smiles>O=c1cc(-c2ccccc2)oc2ccccc12</smiles>

Flavone<smiles>O=c1c(O)c(-c2ccccc2)oc2ccccc12</smiles>

Flavanol<smiles>O=C1CC(c2ccccc2)Oc2ccccc21</smiles>

Flavanone<smiles>O=c1c(-c2ccccc2)coc2ccccc12</smiles>

Isoflavone<smiles>Oc1cc(O)c2c(c1)OC(c1ccc(O)c(O)c1)C(O)C2</smiles>

Catechin<smiles>O=c1c(O)c(-c2ccc(O)c(O)c2)oc2cccc(O)c12</smiles>

Quercetin<smiles>O=C(O)c1cc(O)c(O)c(O)c1</smiles>

Gallate<smiles>O=C(O)/C=C/c1ccc(O)c(O)c1</smiles>

Caffeic acid<smiles>COc1cc(/C=C/C(=O)O)ccc1O</smiles>

Ferulic acid<smiles>C=CCS(=O)CC=C</smiles>

Allicin<smiles>O=C(/C=C/C=C/c1ccc2c(c1)OCO2)N1CCCCC1</smiles>

Piperine<smiles></smiles>

Anthocyanin

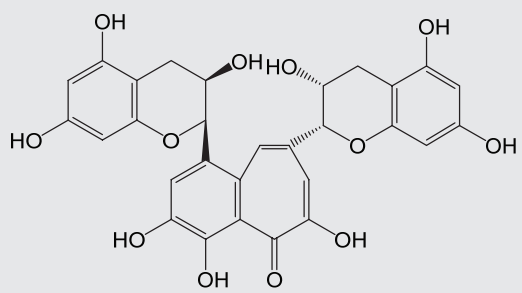

Theaflavin<smiles>CC1=C(/C=C/C(C)=C/C=C/C(C)=C/C=C/C=C(C)/C=C/C=C(C)/C=C/C2=C(C)CCCC2(C)C)C(C)(C)CCC1</smiles>

B-carotene

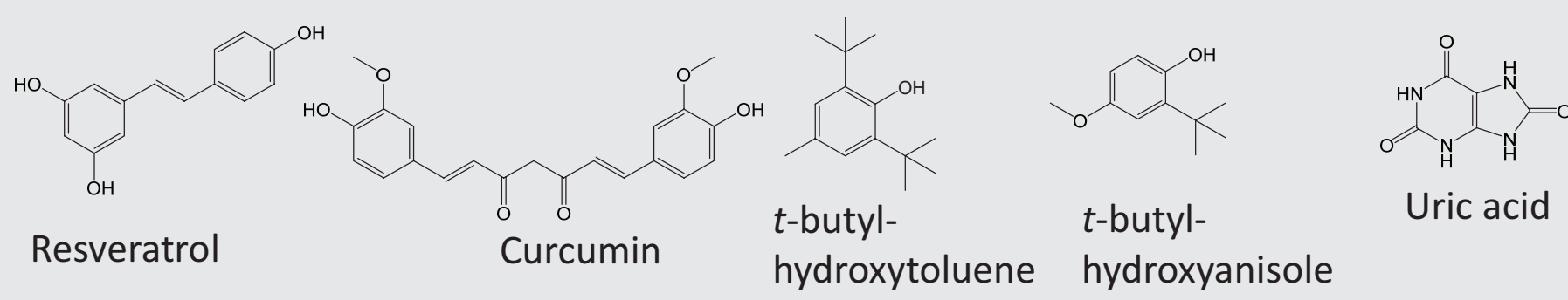

Figure 7. Chemical structures of selected phytoantioxidants.

pre-existent chronic disease. Elevated markers of oxidative stress are uniformly present in these patients, oxidative stress is thought to have a central pathological role in the most common diagnoses in ICU patients, including acute respiratory distress syndrome (ARDS), diaphragmatic fatigue, cardiogenic shock, renal failure, hepatic failure, brain injury/encephalopathy, sepsis, burns, and disseminated intravascular coagulation. ${ }^{45-52}$ Increased oxidative stress is evident from high levels of biomarkers of oxidative stress, such as reactive oxygen species (ROS), free radicals, protein-aldehyde adducts, and inflammatory cytokines. ${ }^{9,21}$ High levels of these markers have been reported in expired breath, blood, and tissues of ICU patients with multiorgan failure and are associated with greater morbidity and mortality. ${ }^{53-56}$ Reactive oxygen species trigger the secretion of inflammatory cytokines; many of the same cytokines can trigger production of ROS from the mitochondria and other oxidative organelles in cells, a self-perpetuating cycle. Besides cytokines, the release of other chemical and biological promoters of oxidative stress (i.e., free fatty acids, leukotrienes, prostaglandins, thromboxanes) from damaged tissues and infiltrating inflammatory cells further tilts the delicate balance between antioxidants and pro-oxidants towards the latter, and an inexorable amplification of injury results. ${ }^{49,53,54,57-61}$ 
Chemical and biological antioxidant factors, which should limit tissue damage caused by oxidative stress, are depleted in some ICU patients. ${ }^{62,63}$ Critically ill patients have decreased plasma and intracellular levels of chemical antioxidants (free radical scavengers), decreased levels of biological antioxidant chemicals, particularly glutathione (GSH), decreased activity of numerous antioxidant enzymes, and increased levels of pro-oxidants, such as heavy metals. ${ }^{54,57}$ Oxidative stress lowers plasma levels of $\alpha$-tocopherol and ascorbate, the primary physiological free radical scavengers, and increases levels of oxidized glutathione (GS-SG), a pro-oxidant. Increased lipid peroxides have been inversely correlated with low concentration of vitamin C. ${ }^{46,51}$ Plasma levels of vitamin $C$ are reported to be low in multiorgan failure. ${ }^{46,51}$ Antioxidant enzymes decreased by oxidative stress can include superoxide dismutase (SOD), catalase (CAT), glutathione peroxidase (GPx), glutathione-reductase (GR), $\gamma$-glutamyl transpeptidase (GGT), xanthine oxidase (XO), and glucose 6-phosphate dehydrogenase (G6PD). ${ }^{49,50,64-68}$ Reduced detoxification of free radicals of oxygen and nitrogen are correlated with an increased risk of death in patients with sepsis. ${ }^{69}$

Oxidative stress has a central pathogenic role in respiratory failure due to ARDS. The transcription factor central to the production of inflammatory cytokines, $\mathrm{NF} \kappa \mathrm{B}$, is strongly activated in the alveoli of patients with ARDS ${ }^{62,63}$ Unfortunately, mechanical ventilation, the primary modality for treating ARDS, itself exacerbates oxidative stress. Mechanical ventilation increases oxidant production in diaphragmatic myofibers resulting in atrophy and contractile dysfunction ${ }^{70-72}$ and damages lungs with high partial pressures of inspired $\mathrm{O}_{2}$ and by barotrauma through oxidant mechanisms. Mechanical ventilation is also associated with lowered plasma levels of many nutrients with antioxidant properties and high levels of lipid peroxidation throughout the course of ARDS ${ }^{58}$ These alterations can also accelerate damage to other vital organs.

Underlying chronic cardiovascular disease (CVD), acute cardiac events, and consequent circulatory collapse also occur in ICU patients. ${ }^{54,55}$ Cardiovascular disease risk factors (CVDR), including age, gender, obesity, smoking, hypertension, diabetes mellitus, hyperlipidemia, dyslipidemia, and insulin-resistance, are the most significant independent CVD risks (CVDR). ${ }^{9,73-77}$ The pathogenesis of these CVDR is strongly linked to oxidative stress. Age is perhaps the most important, obviously irreversible. Overwhelming evidence supports cumulative genomic damage due to oxidative stress as the underlying pathophysiology of normal aging. Low chronically increased rates of oxidative damage, such as that caused by behavioral factors (smoking) or environmental exposures (heavy metals, chronic infections, etc.), accelerate aging. ${ }^{78}$ Senescence of tissues and organs lead to numerous age-associated degenerative disorders, including cancer, insulin resistance, obesity, metabolic syndrome, type II diabetes, inflammatory arthritis, atherosclerosis, and neurodegenerative disease. Since the elderly are frequently afflicted with these diseases, even minor illnesses, such as urinary tract infections and upper respiratory tract infections, can precipitate admissions to the ICU and progression to multiorgan failure..$^{54,55}$

Given the high prevalence of subclinical CVD in patients admitted to ICU, there is a very high incidence of acute cardiac events, such as congestive heart failure, arrhythmias, peripheral vascular occlusion, and myocardial infarction. ${ }^{79,80}$ Atherosclerosis is the underlying pathology for each, hypertension is the chief contributor to vascular degeneration, and oxidative stress is the molecular underpinning of hypertension. Free radicals promote vascular smooth muscle growth causing increased peripheral vascular resistance and endothelial 'stickiness' that enhances recruitment of macrophages and monocytes into the vessel wall. In patients with hyperlipidemias, the accumulation of oxidized lipid in these plaques accelerates their growth, and oxidative stress promotes oxidized lipid nanoparticles (chiefly LDL and HDL) that bind to damaged endothelium. ${ }^{81-83}$ Behavioral factors, such as smoking, excess calorie and salt intake, sedentary lifestyle, and obesity, predispose to hypertension. Powerful alkylating toxins and oxidative and nitrosamine compounds (nitrogen-containing free radicals) are abundant in cigarette smoke. Insulin resistance that accompanies obesity strongly predisposes one to the metabolic syndrome and type II diabetes, and oxidative stress is key to the pathogenesis of each of these CVDR. Levels of lipid peroxidation and DNA damage are higher in diabetic patients. 
Beyond hyperlipidemia that is nearly universally present in obese or diabetic patients, hyperglycemia itself promotes formation of ROS and decreases the levels of natural antioxidants. ${ }^{83-85}$

Renal failure is present in a substantial proportion of ICU patients, many with pre-existent kidney disease. Systemic oxidative stress has a critical role in physiological renal blood flow (RBF) and in the pathophysiology of several kidney diseases. ${ }^{9,86}$ P47phox-containing NAPDH oxidases NOX1 and NOX2 are major ROS generators in kidney glomeruli, leading to acute kidney injury (AKI). ${ }^{85,87}$ Hypertension is the chief factor in accelerating nephrosclerosis with age. Atherosclerosis of renal blood vessels reduce renal blood flow (RBF) but the rich blood supply and abundant mitochondria make the kidney susceptible to oxidative stress that leads to autophagy in AKI. ${ }^{87,88}$ Physiological vasodilators that regulate $\mathrm{RBF}$ include the nitric oxide free radical (NO•) and physiological products of cyclooxygenase (COX1/2)-catalyzed lipid peroxidation products, such as prostaglandins $E_{2}$ and $I_{2}$. Reperfusion after ischemic renal damage causes formation of the superoxide anion radical $\left(\mathrm{O}_{2}^{-*}\right)$ which interferes with production of $\mathrm{NO} \cdot{ }^{89-91}$ Oxidative endothelial injury results in anatomical heterogeneity in the expression of inducible and endothelial nitric oxide synthase (iNOS and eNOS), enzymes that use arginine as a substrate to generate $\mathrm{NO}$ - leading to focal ischemia and renal damage. ${ }^{92}$ The iNOS-dependent inhibition of eNOS (endothelial NOS) further exacerbates endothelial damage..$^{89,90}$

As in acute coronary syndromes, reperfusion after an ischemic event results in a wave of oxidative stress with generation of ROS. A large number of intracellular molecules that comprise the damage-associated molecular patterns (DAMPs) are released from cells damaged by ROS. DAMPs activate inflammation by activating toll-like receptors (TLR), a family of pattern recognition receptors (TLR1-10) expressed on lymphocytes, macrophages, and dendritic cells. TLR activation increases the release of additional DAMPs, thereby forming a positive feedback paracrine loop that amplifies inflammation and consequent tissue damage. ${ }^{69,93}$ TLR4 activation directly amplifies ROS formation by activating NADPH oxidase, a membrane bound enzyme found on endothelial cell surfaces that produces $\mathrm{O}_{2} \cdot{ }^{\cdot \bullet 8,94}$ Prominent among DAMP proteins are the heat shock proteins (HSPs) and high-mobility group box-1 (HMGB-1) proteins. Although intracellular HSPs protect cells, secreted HSPs can potentiate damaging inflammation. Similarly, extracellular HMGB-1 induces inflammation by binding TLRs. ${ }^{88,94}$ Oxidative stress and inflammation also induce mitochondrial depolarization and dysfunction that increases ROS formation.

Liver dysfunction and injury occurs frequently in critically ill patients. Oxidative stress is implicated as a cause as well as an effect of liver damage. Excess ROS production is the central pathological mechanism in the initiation and progression of acute liver damage $^{54,95}$ as well as chronic liver diseases, such as chronic viral hepatitis, alcoholic liver diseases, and non-alcoholic steatohepatitis. ${ }^{95,96}$ Although alcohol dehydrogenase can metabolize alcohol relatively safely to acetaldehyde that is converted to acetate by mitochondria, chronically high alcohol consumption results in a relative increase in alcohol metabolism by the cytochrome p450 enzyme CYP2E1, a pathway that generates ROS. Alcohol can reduce the expression of antioxidant enzymes and levels of GSH, which normally protect hepatocytes. Increased ROS cause damage to mitochondria, and damaged mitochondria release even more ROS. Acetate production from metabolism of alcohol promotes synthesis of lipids, which are substrates for formation of lipid peroxy radicals upon reaction with ROS. NRF2, a transcription factor, regulates the expression of a large number of antioxidant proteins and enzymes. ${ }^{97,98}$ The protective effects of NRF2 are also mediated by stimulating fatty acid metabolism by increasing the expression of many fat metabolizing proteins, such as CD36. ${ }^{99,100}$ Alcohol and viral infections impair NRF2 expression. ${ }^{101}$ Inflammation in response to viral infection promotes ROS production. Hepatic iron accumulation significantly exacerbates the damaging effects of alcohol and viruses by directly initiating and promoting lipid peroxidation. . $^{9,101,102}$

Many ICU patients have underlying traumatic brain injury (TBI). Oxidative stress markers, such as lipid peroxides, reactive oxygen species, reactive nitrogen species, and carbonylated proteins, are increased in the brain as well as the blood and peripheral tissues 
of patients with TBI. ${ }^{103,104}$ The chief biological antioxidant molecule, glutathione (GSH), is reduced, and the level of oxidized GSH (glutathione-disulfide, GSSG) is increased. The activity of GSH-linked antioxidant enzymes, such as glutathione peroxidase (GPx), glutathione-reductase (GR), and glutathione Stransferase (GST), is decreased. The activity of glucose 6-phosphate dehydrogenase (G6PD), an enzyme necessary for providing reducing equivalents (NADPH) to GR for reducing GSSG to GSH, is also decreased in the blood and tissues of patients with TBI. ${ }^{105-107}$

\section{ANTIOXIDANT THERAPY IN CRITICAL ILLNESS}

Despite the pervasive role of oxidative stress in the pathogenesis of multiorgan failure, the development of antioxidant strategies to counteract oxidative stress has not met with great success in clinical trials. Numerous studies have evaluated the effects of antioxidants in critical care patients, and results have been quite inconsistent; some studies show benefit, others no efficacy, and others harm. ${ }^{108-113}$ In a large clinical trial, it is found that supplementation of ICU patients with selenium, zinc, $\beta$-carotene, vitamin, vitamin $C$, or glutamine (a precursor for glutathione) had no therapeutic benefit. $^{35,114,115}$ In fact, glutamine supplementation appeared to be harmful in critically ill patients with multiorgan failure. ${ }^{114}$ Manzanares et al reported a systemic review and meta-analysis of randomized trials suggesting that antioxidant supplementation may improve outcomes of critically ill patients, particularly those at highest risk of death. ${ }^{35}$

Since GSH and GSH-linked enzymes are important biological antioxidants that are depleted in patients with multiorgan failure, interventions that increase their levels should reduce oxidative stress. Since GPx is a selenium containing antioxidant enzyme that is known to lose activity in experimental selenium deficiency, selenium supplementation should theoretically reduce oxidative stress. In a single center clinical trial conducted with 54 septic patients, high-dose selenium administration did not reduce 28 day mortality but did increase the activity of GPx. No effect on the levels of inflammatory cytokines was noted. However, selenium administration was associated with reduced incidence of ventilator-associated pneumonia. ${ }^{115}$ In a recent multicenter randomized controlled trial (RCT), high-dose intravenous administration of sodium selenite was combined with procalcitonin-guided antimicrobial therapy to study sepsis outcomes. Both interventions failed to improve 28 day mortality. ${ }^{116}$ In the most recent meta-analysis reviewing 21 RCTs, the investigators concluded that parenteral supplementation of selenium in critically ill patients as a single agent or combined with other antioxidants had no effect on mortality, infections, length of stay, or ventilator days. ${ }^{115} \mathrm{~N}$-acetylcysteine (NAC) is a sulfhydryl antioxidant that can augment GSH levels and modulate immunity. ${ }^{67,68}$ It stimulates neutrophil phagocytosis in patients with SIRS, sepsis, and multiple trauma. ${ }^{64}$ In a prospective double blind study, NAC administration increased hepatic perfusion, improved liver function tests, and increased the cardiac index in sepsis patients. ${ }^{65}$ Other studies have reported no change in the levels of cytokines or improvement in outcomes. In fact, one study reported that sepsis-induced organ failure increased. ${ }^{64}$

Many drugs commonly used during treatment of critically ill patients are themselves antioxidants. Perhaps the most important are the HMG-CoA reductase inhibitors (statins), the most commonly prescribed drugs in the world. Beyond simply lowering LDL cholesterol, statins exert antioxidant effects through multiple effects on NADPH oxidase, myeloperoxidase, catalase, paroxanase, and nitric oxide synthases. ${ }^{117-119}$ Angiotensin converting enzyme inhibitors can exert antioxidant effects directly by scavenging free radicals and by blocking the pro-oxidant effects of angiotensin signaling. ${ }^{120,121}$ Diuretics, such as hydrochlorothiazide and spironolactone, may exert antioxidant effects through reduction of matrix metalloproteinase enzymes. ${ }^{122}$ Adrenergic agents used for blood pressure support, such as dobutamine, dopamine, and isoproterenol, are potent scavengers of free radicals. ${ }^{123}$ Their free radical scavenging effects may be attributed to phenolic hydroxyl groups. ${ }^{28}$ Indeed, the augmentation of the ionotropic effects by ascorbate supports the antioxidant mechanism of dobutamine. ${ }^{124}$ Certain bronchodilator drugs, such as tiotropium, may also exert antioxidant effects. ${ }^{125,126}$ Heparin increases the antioxidant effect of superoxide dismutase by releasing it near the endothelial cells of vessels, and it 
has an antioxidant role by removing free radicals. ${ }^{127,128}$ Chelating agents that bind to metals, such as iron, can reduce the concentration of nonprotein bound iron, and subsequent renal excretion reduces the level of accumulated iron. In patients with iron overload state, total body iron can be lowered by chelation in patients who are anemic and by phlebotomy in those who are not. Anti-inflammatory agents reduce the formation of many PUFA by inhibiting cyclooxygenase or lipoxygenase enzymes. Successful treatment of infection will also lower oxidative stress. Antibodies targeted to deplete inflammatory cytokines, such as TNF or IL6, also lower oxidative stress by reducing inflammation.

Several other drugs with antioxidant or antiinflammatory activities in vitro are being evaluated in critically ill patients. Ketanserin is a serotonin receptor $2 \mathrm{~A}$ antagonist that exerts antihypertensive and anti-inflammatory effects. ${ }^{129-131}$ It can suppress cigarette smoke induced release of the inflammatory cytokine interleukin-8 (IL8) through an NRF2 mediated mechanism and increase the GSH/GSSG ratio in vitro. It may also inhibit iNOS expression via the MEK/ERK pathway. ${ }^{130} \mathrm{It}$ has been reported to improve baroflex function ${ }^{129}$ and improve lung function in COPD patients. ${ }^{132,133}$ In one open label pilot study it improved microcirculatory perfusion in septic patients. ${ }^{129}$ Melatonin, an over-the-counter drug for treatment of insomnia, appears to exert antiinflammatory, antiapoptotic, and antioxidant effects. It reverses mitochondrial dysfunction and has beneficiary effects in animal models of septic shock. ${ }^{134-136}$ In one study of healthy human volunteers, melatonin lowered lipopolysaccharide-induced inflammation and oxidative stress. ${ }^{137,138}$ The mitochondria targeted free radical scavenging compound MitoQ (triphenylphosphonium ubiquinone) showed protective effect by decreasing hydrogen peroxide-induced apoptosis and deceasing biochemical markers of acute liver and renal dysfunction. ${ }^{139-141}$ In in vitro studies and needs more studies in human.

The proceeding paragraphs discuss a few of the drugs used in the treatment of critically ill patients with multiorgan failure. Indeed, failure to control for their effects may underlie the failure of clinical trials to demonstrate beneficial effects from any given antioxidant intervention. Because all free radical scavengers are obligatory oxidants at concentrations greater than those at which they exert optimal antioxidant effects, the inability to titrate doses to optimal antioxidant effects is a central problem in designing optimal trials to test antioxidants. Having appropriate mechanistically based biomarkers that could identify the exact redox state necessary for optimal healing of patients with multiorgan damage would overcome this problem. Understanding the complexities of the central chemical process in oxidative stress, lipid peroxidation, is required for developing such markers. ${ }^{142,143}$

\section{GLUTATHIONE-LINKED BIOLOGICAL ANTIOXIDANTS}

GSH ( $\gamma$-glutamyl-cysteinyl-glycine) (Figure 8) is a sulfhydryl containing peptide that represents the dominant nonprotein thiol in eukaryotic cells. The thiol $(-\mathrm{SH})$ group of $\mathrm{GSH}$ is a nucleophile (electron rich, Lewis base) which reacts with electrophilic (electron poor, Lewis acids) chemicals that would otherwise form adducts with DNA bases containing nitrogen with similar reactivity with electrophiles as the GSH thiol group. It also prevents the formation of electrophilic adducts with protein thiols, serving as a protective buffer that prevents DNA and protein damage by electrophiles. Formation of $\mathrm{GSH}$ electrophile adducts (GS-E) is catalyzed by a family of enzymes, glutathione S-transferases (GSTs). ${ }^{144,145}$ Metabolic degradation of lipid hydroperoxides yields many highly damaging reactive electrophiles that are metabolized by conjugation with GSH. This is the first step in the metabolism and renal excretion of electrophilic toxins through the mercapturic acid pathway (Figure 8). In addition to the physiologically formed lipid-derived electrophiles, this pathway also metabolizes exogenous electrophiles that include all alkylating agent chemotherapy drugs and metabolites of drugs, such as acetaminophen. The major route of metabolism of 4-HNE is through the mercapturic acid pathway. ${ }^{146}$

Because electrons are not transferred in adduct formation to form GS-E, these are not redox reactions. GSH mediates antioxidant functions by undergoing redox reactions in which its oxidation to the GSH-disulfide, GS-SG, a dimer of GSH, is coupled 


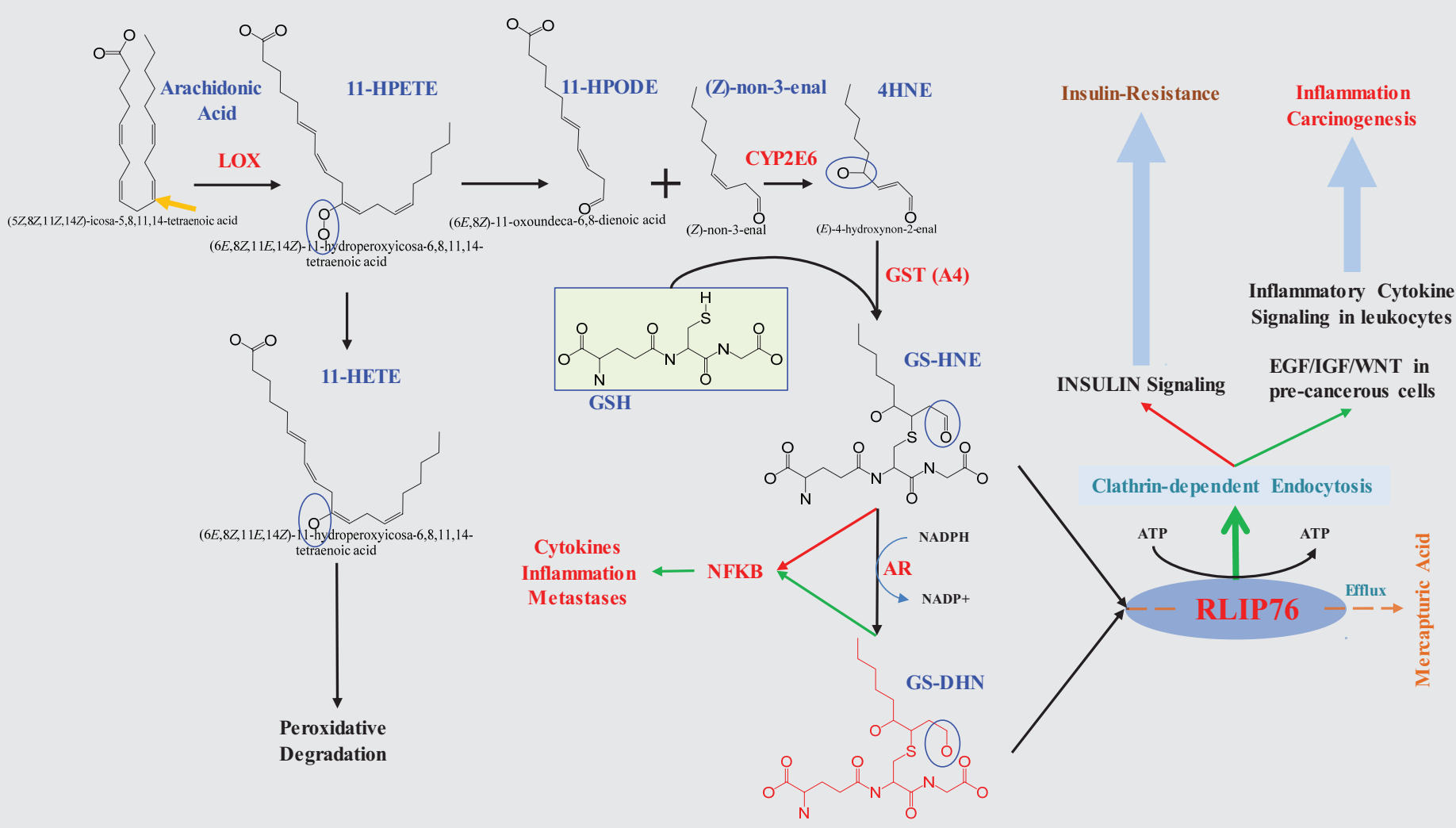

Figure 8. Role of the mercapturic acid pathway in 4-hydroxynonenal generation and disposition.

Arachidonic acid released from diacylglycerol by phospholipase A2 undergoes linear peroxidation catalyzed by lipoxygenase (LOX - specifically, ALOX15). The resultant 11-hydroperoxyeicosatrienoic acid (11-HPETE) spontaneously degrades to 11-hydroperoxydienoic acid (11-HPODE) and the (Z)-non-3-enal, which is then catalytically converted to 4HNE by cytochrome p450 isozyme CYP2E6 (and others). Glutathione S-transferase isozyme 4 (GSTA4, and others) catalyze the glutathionylation of 4HNE to form glutathionyl-HNE (GS-HNE). Aldose reductase (AR) uses NADPH to reduce the aldehyde group of GS-HNE to an alcohol resulting in formation of glutathionyldihydroxynonenol (GS-DHN). GS-HNE inhibits NFKB activation, whereas GS-DHN stimulates it. Both GS-HNE and GS-DHN are transported out by Rlip coupled with ATP hydrolysis. This is a necessary for certain steps in clathrin dependent endocytosis (CDE). CDE functions to inhibit insulin signaling, whereas EGF/IGF/WNT and cytokine signaling are activated by CDE. Thus, inhibition of Rlip results in increased insulin signaling and decreased carcinogenesis and inflammation.

with reduction of $\mathrm{LOOH}$ and other toxic oxidants that would otherwise cause apoptosis or DNA damage. ${ }^{147}$ The selenium containing enzymes, glutathioneperoxidases (GPXs), catalyze the reduction of $\mathrm{H}_{2} \mathrm{O}_{2}$ coupled to a 2-electron oxidation of $\mathrm{GSH}$ to form
GSSG. ${ }^{148}$ Selenium deficiency creates a powerful pro-oxidant state because it impairs GPX function. The $\alpha$-class GST isozymes GSTA1-4 also catalyze the reduction of hydroperoxides. Unlike GPX, which primarily reduces $\mathrm{H}_{2} \mathrm{O}_{2}(\mathrm{HOOH})$, GST $\alpha$ also uses $\mathrm{LOOH}$ 
as substrates, serving as a crucial mechanism for terminating oxidative stress by consuming the chief propagator and amplifier of lipid peroxidation. Glutathione reductase (GR) and glucose 6-phosphate dehydrogenase (G6PD) function in conjunction to regenerate GSH from GSSG using a pair of electrons from NADPH. Thus, GR and G6PD serve as the backbone of GSH-linked biological antioxidant defenses. ${ }^{147}$ Loss, inhibition, or mutation induced catalytic dysfunction of any of these GSH-linked enzymes increases lipid peroxidation. The importance of maintaining physiological concentrations of GSH to prevent tissue damage is evident from hemolytic anemia caused by G6PD deficiency and hepatic necrosis caused by acetaminophen overdose. ${ }^{147,149,150}$

\section{RLIP AND THE MERCAPTURIC ACID PATHWAY}

The GS-E generated in cells through formation of adducts with electrophiles are highly anionic and thus not membrane permeable. Upon accumulation in cells, they can undergo chemical rearrangements to form many toxic compounds. GS-Es are also potent inhibitors of GST, GR, and other enzymes that utilize GSH, and removal of GS-E from cells is necessary to maintain the enzymatic functions of these enzymes. ${ }^{147,149,150}$ GS-Es are removed from cells by several ATPdependent plasma membrane transporters that catalyze their efflux from cells. Extracellular GS-Es are degraded sequentially by cell surface enzymes, $\gamma$-glutamyl transpeptidase (GGT) and dipeptidases, to cysteinyl-electrophile conjugates that are $\mathrm{N}$-acetylated to mercapturic acid in the kidneys. The formation and metabolism of $4 \mathrm{HNE}$ to mercapturic acid are shown in Figure 8.

Despite concerted research effort over decades, the GS-E transport proteins remained elusive. We first described a membrane transporter designated DNP-SG ATPase that catalyzes the ATP-dependent efflux of GS-E from cells. Through purification and cloning of DNP-SG ATPase, we demonstrated its identity with Ral-binding protein1 (aka Ralbp1, RLIP76, referred to here as Rlip). ${ }^{151,152}$ Rlip had been cloned by other investigators as a Ral-binding effector protein involved in endocytosis but without known molecular function. We demonstrated that the recombinant Rlip protein could be purified by the same methods used for DNP-SG ATPase and showed that it catalyzed the transmembrane transport of GS-E coupled with ATP-hydrolysis ex vivo and in vivo. ${ }^{153-155}$ We showed that knockout mice that had no Rlip gene had $80 \%$ loss of GS-E transport activity and markedly increased levels of $\mathrm{LOOH}$ and $4 \mathrm{HNE}$ in tissues. These mice were also severely deficient in clathrin-dependent endocytosis. ${ }^{156,157}$ Other transporters, such as the multidrug-resistance protein (MRP), constitute the mechanisms that mediate the residual function. Unlike the high capacity, low affinity efflux function of DNP-SG ATPase, MRP related proteins constitute a high affinity, low capacity efflux mechanism necessary in leukocytes and the liver. Indeed, inhibitors of MRP (i.e., montelukast) are used as anti-inflammatory drugs for a wide variety of applications, including asthma and allergic reactions. Inhibitors of MRP, however, proved toxic upon systemic administration due to cholestatic hepatitis, indicating its importance in efflux of bilirubin metabolites.

Our studies of Rlip in cancerous and noncancerous cultured cells and in knockout mice have established that Rlip is a stress-responsive, anti-apoptotic protein that protects against radiant (heat, U.V. light, and X-ray) and chemical (doxorubicin, cyclophosphamide, melphalan) poisoning. Indeed, the antiapoptotic effect of Rlip is sufficiently potent that the recombinant protein has been developed into the most effective drug for the prevention and treatment of radiation poisoning. ${ }^{158-162}$ Because of the prevailing theory that oxidative stress itself causes insulin- resistance, the underlying physiological defect in metabolic syndrome, diabetes, and obesity, we expected that Rlip mice would exhibit these conditions. Due to the prevailing theory of carcinogenesis, accelerated accumulation of DNA damage leading inexorably to malignant transformation, we anticipated that these mice would have greater than usual susceptibility to chemical carcinogens. Given the mutually reinforcing relationship between oxidative stress and inflammation, we expected greater susceptibility to inflammation and higher levels of inflammatory cytokines. 
Finally, given the oxidative stress theory of aging, we expected them to be short lived.

The finding that the loss of GS-E transport increased lipid hydroperoxides, $\alpha, \beta$-unsaturated carbonyls, and glutathione-conjugates of $4 \mathrm{HNE}$ were consistent with our predictions from in vitro studies. In addition, the mice indeed had slightly shorter life spans. Surprisingly, however, they actually had an antimetabolic syndrome phenotype; they were insulin sensitive, hypoglycemic, hypocholesterolemic, hypotriglyceridemic, and nearly completely resistant to obesity. ${ }^{14,159}$ Administration of very low doses of insulin caused hypoglycemic death. Their baseline low levels of blood glucose were unaffected by metformin or rosiglitazone. ${ }^{14,159}$ The targets of metformin and rosiglitazone (PPAR $\gamma$ and PPAR $\alpha$ ) were maximally elevated. Triglycerides at baseline were equal to that achieved with the hypotriglyceridemic drug gemfibrozil in wild-type mice. Similarly, atorvastatin had no effect on their already $40 \%$ lower cholesterol levels at baseline. ${ }^{14,150,159,163}$ In addition to significantly reduced weight gain upon being fed a high fat diet, they had low levels of inflammatory cytokines that did not increase with over feeding. The tight coupling and positive correlation between increased oxidative stress with cytokine levels universally found in numerous previous model systems ranging from cell culture to animals and humans was absent in Rlip knockout mice. It appeared that oxidative stress failed to translate into the clinical metabolic end points associated with oxidative stress. ${ }^{14,150,159,163}$ The critical importance of clathrin dependent endocytosis (CDE) in transmission of signals that activate cytokine expression and release could be a potential reason. ${ }^{157}$ We had previously shown that GS-E transport was tightly coupled to CDE; mutations of Rlip at its GS-E binding site that caused loss of GS-E transport were associated with a parallel decrease in CDE of epidermal growth factor and insulin. A potential explanation for insulin sensitivity of these mice was that CDE serves to terminate insulin signaling; thus deficiency of CDE would be expected to intensify and prolong insulin effects. ${ }^{157}$

Unlike insulin, the growth inducing effect of epidermal growth factor require endocytosis before the assembly of signaling complexes on the surface of endocytic vesicles. we found that embryonic fibroblasts from Rlip-deficient mice were deficient in downstream signaling to growth stimulating kinases. ${ }^{160,161,164-167}$ We had previously shown that depletion of Rlip by specifically targeted antisense oligonucleotides or silencing RNAs caused death of a number of histological types of cancer cells in culture. This effect was replicated by anti-Rlip antibodies that block GS-E transport by binding to an $\mathrm{N}$-terminal domain epitope of Rlip. All cancer cell types tested were more sensitive to apoptosis upon depletion or inhibition of Rlip compared with any nonmalignant cell types of ectodermal, endodermal, or mesodermal lineages, indicating that the function of Rlip was more important for cancer cells than normal cells. ${ }^{160,161,164-167}$ This is perhaps understandable because cancer cells are more susceptible to apoptosis by alkylating agents, 4HNE, and lipid-hydroperoxides, and given their higher metabolic rate and generation of ROS, they require a greater capacity to eliminate toxic metabolites than normal cells. ${ }^{168}$ It should be noted that, like insulin, the proapoptotic effects of death receptor mediated apoptosis is antagonized by endocytosis. Thus, greater sensitivity to the extrinsic pathway of apoptosis could account for the greater sensitivity of malignant cells to Rlip inhibition. Cell culture studies showing that cancer cell growth is inhibited and apoptosis is triggered by inhibiting or depleting Rlip were translated in vivo in a series of studies showing that anti-Rlip antibodies as well as Rlip antisense or siRNA caused dramatic regression of cancers in mice. ${ }^{164}$ We first demonstrated this in a syngeneic murine model of melanoma in immunocompetent mice. ${ }^{167}$ Unlike previous results of numerous type of therapies in this model that had shown growth delays without actual regression, our studies showed dramatic and sustained regression of melanoma. Subsequent studies of human cancer cells xenografted in immunodeficient mice demonstrated that targeted inhibition or depletion of Rlip caused sustained regression of established tumors of small cell lung cancer, nonsmall cell lung cancer, colon cancer, pancreatic cancer, prostate cancer, kidney cancer, and neuroblastoma. ${ }^{160,161,164-167}$ In recent unpublished studies, we have observed similar results in breast cancer. 
The mice gained weight normally despite near complete systemic depletion of Rlip in the major organs. Additionally, Rlip depletion pharmacologically caused hypoglycemia as was observed in the congenitally Rlip-deficient mice. ${ }^{163}$

Gene expression analyses of Rlip knockout mice had shown a relatively small number of differentially expressed genes. Chaperone proteins and multiple stem cell transcription factors as well as xenobiotic metabolizing and antioxidant enzymes were most prominent. Interestingly, others had shown that Rlip was a key regulator of the master transcription factor for chaperones, HSF1. ${ }^{158,169}$ Their studies confirmed the stress and heat responsive accumulation of Rlip protein, and their results indicated that Rlip bound to tubulin fibers sequesters HSF in the cytoplasm and that stress causes dissociation of the two proteins with translocation of HSF1 into the nucleus to activate chaperone transcription. ${ }^{158,169}$ We confirmed these studies and also showed that Rlip concomitantly translocates to the plasma membrane as well. In addition, Rlip was also found to translocate to discrete foci in the nucleus, suggesting a transcription regulatory function.

Most remarkably, Ingenuity Pathways Analysis of the differential expression of genes in Rlip deficient mice showed that the primary upstream regulator of differentially expressed pathways was p53. ${ }^{164}$ This finding was consistent with the fact that both p53 and Rlip are stress-responsive proteins. However, there is one fundamental difference between p53 and Rlip; over-expression of Rlip confers an anti-apoptotic phenotype, whereas p53 activation caused by severe stress triggers apoptosis. Inhibition by p53 of GS-E transport by purified recombinant Rlip reconstituted in artificial liposomes supported the idea of mutually opposed functions of Rlip and p53, with the former acting to defend cells from apoptosis (in response to survivable stress) and the latter triggering suicide upon catastrophic stress. The most important evidence for opposite effects of p53 and Rlip was the cancer susceptibility phenotypes of p53 vs. Rlip knockout mice; the former are universally susceptible to death due to cancer at an early age, whereas the latter were resistant to carcinogenesis caused by the most powerful known chemical carcinogens, benzopyrene and dimethylbenzanthracene. ${ }^{164}$ Taken together, the evidence of the antineoplastic activity of Rlip-depletion on established cancer and resistance to carcinogenesis in Rlip-deficient mice led us to hypothesize that Rlip has crucial importance in cancer cells. Its presence appears to be required for the genesis of cancer and subsequently for the survival and growth of cancer cells.

To test this hypothesis, we created double knockout mice that lacked one or both copies of p53 and Rlip. We found that no mice lacking even one copy of Rlip developed spontaneous cancer regardless of whether one or both copies of p53 were absent. ${ }^{164}$ Indeed, the balanced double heterozygote mice were resistant even to benzopyrene-mediated carcinogenesis. To determine whether pharmacologically created Rlip deficiency could also prevent cancer, we administered Rlip antisense (R508) intraperitoneal weekly starting at age 9 weeks to p53 homozygous knockout mice. ${ }^{164}$ We observed $100 \%$ survival without evidence of any malignancy in p53 homozygous knockout mice that were made Rlip deficient by the Rlip antisense. Most remarkably, the treatment reduced Rlip by only approximately $50 \%$, essentially equivalent to a heterozygous Rlip knockout mouse. Therefore, hemizygous deficiency of Rlip was sufficient to switch off the spontaneous carcinogenesis phenotype of p53 knockout mice. No previous genetic or pharmacological intervention had prevented spontaneous neoplasia in p53 knockout mice, despite over 3 decades of research. ${ }^{164}$ Interestingly, p53 deficient mice with Rlip deficiency develop no cancer but continue to have similar levels of oxidative DNA damage as control p53 knockout mice. Thus, DNA damage did not translate into malignant transformation in the setting of Rlip deficiency in these mice. ${ }^{164}$

To investigate the mechanism, we analyzed hepatic tissues to compare signaling effects known to occur downstream of TNF, EGF, and other growth factors. We found that the cancer free R508 treated p53 null mice had signaling protein levels quite similar to wild type. ${ }^{164}$ We performed complete epigenomic and transcriptomic profiling of 40 week old R508-treated cancer free p53 homozygous knockout mice. Since there had never been any p53 null cancer free mice at this 
age, the results provided novel insight not only into the molecular mechanisms of carcinogenesis, but also into the genomic effects of p53 deficiency (without the secondary effects of the presence of cancer). ${ }^{164}$ We found a remarkably normal promoter methylation profile, essentially resembling wild type. Nonrandom promoter methylation defects observed in p53 null mice were reduced by $95 \%$ in mice treated with R508. These promoter methylation changes correlated with transcriptomic changes, indicating a functional relationship between the epigenetic alterations and gene transcription. ${ }^{164}$ By examining the intersection set of differentially promoter methylated and expressed genes between Rlip null and R508-treated p53 null mice, we found that the differentially expressed genes in Rlip null mice were altered nearly identically in the R508-treated p53 null mice. ${ }^{164}$ Thus, we discovered a set of genes, which when differentially expressed, could prevent the transition from DNA damage (the first hit) to malignant transformation (the second hit). This set of genes was enriched in number of known as well as unknown stem cell transcription factors. Importantly, all four Yamanaka (original stem cell genes, the discovery of which resulted in a Nobel Prize for Dr. Yamanaka) were differentially promoter methylated and expressed. Additionally, we found that the most prominent expression changes were in glutathione metabolism, drug metabolism, drug transport, endocytosis, and vesicle transport genes. Taken together, these studies have culminated in overwhelming evidence for a model in which: 1) Rlip is a stress-responsive, antiapoptotic GS-E transporter that links glutathione metabolism with pro-carcinogenic signaling downstream of CDE; 2) Rlip regulates the redox milieu in cells by acting as the rate limiting step of the mercapturic acid pathway that is responsible for disposition of toxic metabolites generated from lipid peroxidation; 3 ) and most importantly, Rlip is necessary to translate oxidative stress into cancer, metabolic syndrome, diabetes, hyperlipidemia and obesity. ${ }^{14,151-154,169-189}$

\section{IMPLICATIONS IN CRITICAL CARE AND ANTIOXIDANT THERAPY}

This new paradigm has very interesting implications in oxidant mediated organ damage and underscores the dual edged functions of antioxidants, perhaps explaining the failure of antioxidants to benefit patients with multiorgan failure while providing a novel method for titrating optimally beneficial antioxidant doses. Given that Rlip provides protection upon increased expression caused by oxidative stress in cell culture, it is reasonable to conjecture that Rlip induction by stress is a physiological response that protects tissues in critically ill patients. Logically, drugs or other interventions that increase Rlip in tissues should lower oxidative stress and benefit ICU patients. ${ }^{190}$ However, cell culture studies are devoid of effects of either inflammation or renal function. Pharmacological augmentation of Rlip protein in vivo could promote inflammation by augmenting the endocytic functions of inflammatory leukocytes, negating any anti-apoptotic benefit. ${ }^{190,191}$ Additionally, renal dysfunction could result in increased accumulation of toxic GS-E in extracellular fluid, negating the beneficial anti- apoptotic effects on tissue damage. By the same reasoning, interventions that directly inhibit Rlip could reduce inflammation, but promote apoptosis. It appears that direct pharmacological modulation of Rlip to reduce oxidative tissue damage would work on the Goldilocks' principle: just the right level to provide maximal benefit by reducing apoptosis but not exacerbating inflammation.

Because Rlip expression is stress-responsive, it stands to reason that Rlip protein levels in tissue (or plasma) could serve as a surrogate biomarker of oxidative stress that could be useful in monitoring and optimizing the dosage of conventional antioxidant compounds. Because oxidative stress causes increased Rlip expression, an antioxidant should lower Rlip expression. This reasoning is supported by our recent studies showing that an orange-derived antioxidant chemical 2'-hydroxyflavanone (2HF) can actually lower the expression of Rlip at low concentrations. ${ }^{190-198}$ Presumably, this reduced Rlip expression is secondary to reduction of oxidative stress through a chemical (free radical scavenging) antioxidant mechanism. These in vitro studies provide the rationale for a novel approach to optimize antioxidant therapy in ICU patients, namely to use plasma Rlip protein levels to titrate optimal doses of antioxidants. $2 \mathrm{HF}$ is an orally bioavailable compound without detectable toxicities that could be considered for clinical trials to study potential benefit in reducing 
oxidative stress in ICU patients. ${ }^{190}$ Certainly, monitoring plasma Rlip levels could also assist in optimizing the beneficial effects of numerous other natural or pharmacological antioxidants. ${ }^{190}$

\section{SUMmaRY}

Despite overwhelming evidence for oxidative stress being a cause of multiorgan failure in ICU patients, no antioxidant strategy has yet gained clinical acceptance or use. We propose that this is due to a number of factors discussed in this communication, all predicated on the understanding of the chemical nature of oxidative stress and the concentration dependent pro- oxidant effects of antioxidants. The necessity of Rlip for translating oxidative stress into inflammation represent a novel paradigm for a biomarker to optimize antioxidants for maximal benefit in critically ill ICU patients.

\section{ACKNOWLEDgements}

We would like to acknowledge support from the Department of Internal Medicine at Texas Tech University Health Sciences Center, Lubbock TX, University Medical Center, the Southwest Cancer Treatment and Research Center at University Medical Center, and the Ethel S. Neely and Emma S. Treadwell Endowed Professorship, Chair of Excellence, University Medical Center. We would also like to thank Dr. Kenneth Nugent, Department of Internal Medicine TTUHSC, for invitation to write this review.

\section{AbBreViations}

${ }^{1} \mathrm{O}$ - Singlet oxygen; 4HHE- 4-Hydroxyhexenal; 4-HNE- 4-Hydroxynonenal; AKI- Acute kidney injury; AKT- Protein Kinase B; Ang II-Angiotensin II; AP2 (FOS/ JUN heterodimer)- Activator Protein 2; ARDS- Acute respiratory distress syndrome; ATP- Adenosine triphosphate; BHA- Butylated hydroxyanisole; BHT- Butylated hydroxytoluene; CHF- Congestive heart failure; COXCyclooxygenase; CVD- Cardiovascular disease; DAGDiacylglycerol; DAMPs- Damage-associated molecular pattern molecules; DNA- Deoxyribonucleic acid; DNP-SG2,4-Dinitrophenyl-S-glutathione; ERK- Extracellular signal-regulated kinases; eNOS- Endothelial derived NOS; FAK- Focal adhesion kinase; $\mathrm{Fe}^{+2}$ - Ferrous (divalent iron); $\mathrm{Fe}^{+3}$ - Ferric(trivalent iron); G6PD- Glucose 6-phosphate dehydrogenase; GGT- $\gamma$-glutamyl transpeptidase; GPCR- G-protein coupled receptors; GPXsGlutathione-peroxidases; GR- Glutathione reductase; GS-Es- GSH-electrophile adducts; GSH- Glutathione (Tripeptide: $\gamma$-glutamyl- cysteinyl-glycine); GS-SG- GSHdisulfide; GSTs- Glutathione S-transferases; $\mathbf{H}_{2} \mathbf{O}_{2}$ Hydrogen peroxide; HPETE- Hydroperoxyeicosatrienes; HP- Hepoxilins; ICP- Intracranial pressure; IL1, IL2, IL6, IL8, IL10- Interleukins; iNOS- Inducible nitric oxide synthase; L-- Free-radical lipid; LDL- Low-density lipoproteins; LH- Lipid fatty acid chains ; LO•- Alkoxyl radical; LOO- Lipid-peroxy radical; LOOH- Lipid hydroperoxides; LOX-Lipoxygese; LP-Lipoxins; LPS-Lipopolysaccharide; LTC4- Leukotriene C4; LT- Leukotrienes; LXR $\alpha$ - Liver X receptor $\alpha$; MAPKs- Mitogen-activated protein kinases; MEK: Also known as MAP2K or MAPKK- Mitogenactivated protein kinase kinase- is a kinase enzyme which phosphorylates MAPK; MAPK- Mitogen activated protein kinase; MitoQ- Mitochondria-targeted antioxidant; MK2- Mitogen-activated protein kinaseactivated protein kinase 2; Mn-SOD- Manganese superoxide dismutase; MRP- Multidrug-resistance protein; NAC- N-acetyl cysteine; NADP+- Nicotinamide adenine dinucleotide phosphate; NADPH- Reduced form of NADP+; NAPQI- $N$-acetyl-p-benzoquinone imine; NFkB- Nuclear factor kappa-light-chain-enhancer of activated B cells; NOX- NADPH oxidases; $\mathbf{O}_{2^{-}}$Oxygen; $\mathbf{O}_{2}{ }^{-0}-$ Superoxide anion radical; $\mathrm{OH}^{\circ}$-Hydroxyl radical; $\mathbf{p} 47$ phox -Also known as NCF1 (Neutrophil cytosolic factor 1); PCIPercutaneous coronary intervention; PGD2-Prostaglandin D2; PGE2- Prostaglandin E2; PGF2 $\alpha$ - Prostaglandin F2 $\alpha$; PGJ2- Prostaglandin J2; PI- Phosphatidyl inositol; PI3K- Phosphoinositide 3-kinase; PKA- Protein kinase A; PKB- Protein kinase B; PKC- Protein kinase C; PLA2- phospholipase A2; PPAR $\gamma$ - Peroxisome proliferator-activated receptor $\gamma$, PUFA- Polyunsaturated fatty acids ; Ralbp1- Ral-binding protein1; RLIP76- Ralinteracting protein of $76 \mathrm{kDa}$; ROS- Reactive oxygen species; SAPKs- Stress-activated protein kinases-SH-Thiol; SOFA score- Sequential organ failure assessment score; SRSA- slow-reacting substance of anaphylaxis; TLRsToll-like receptors; TNF- Tumor necrosis factor; VSMCsvascular smooth muscle cell. 
Article citation: Meda S, Singh SP, Palade PT, Tonk $S$, Awasthi S. Oxidative stress in intensive care unit patients: a review of glutathione linked metabolism and lipid peroxidation. The Southwest Respiratory and Critical Care chronicles 2019;7(27):7-35

From: Division of Hematology and Oncology, Texas Tech University Health Sciences Center, Lubbock TX (SPS, SA ST); Division of Hematology and Oncology, Texas Tech University Health Sciences Center, Odessa, TX (SM); Department of Pharmacology and Toxicology, University of Arkansas for Med Sciences, Little Rock, AR (PTP)

Submitted: $12 / 6 / 2018$

Accepted: $12 / 21 / 2018$

Reviewer: Kenneth Nugent MD

Conflicts of interest: none

This work was supported in part by DoD

(W81XWH-18-1-0534), USPHS grant CA 77495, and

the funds from Perricone Family Foundation, Los

Angeles, CA to SA.

This work is licensed under a Creative Commons

Attribution-ShareAlike 4.0 International License.

\section{REFERENCES}

1. Darling GE, Duff JH, Mustard RA, et al. Multiorgan failure in critically ill patients. Can J Surg 1988;31(3):172-6.

2. Silfvast T, Pettila V, Ihalainen A, et al. Multiple organ failure and outcome of critically ill patients with haematological malignancy. Acta Anaesthesiol Scand 2003;47(3):301-6.

3. Sakr Y, Lobo SM, Moreno RP, et al. Patterns and early evolution of organ failure in the intensive care unit and their relation to outcome. Critical Care 2012;16(6): R222.

4. Ulldemolins M, Roberts JA, Lipman J, et al. Antibiotic dosing in multiple organ dysfunction syndrome. Chest 2011;139(5):1210-20.

5. Karapetsa M, Pitsika M, Goutzourelas N, et al. Oxidative status in ICU patients with septic shock. Food Chem Toxicol 2013;61:106-11.

6. Trentadue R, Fiore F, Massaro F, et al. Induction of mitochondrial dysfunction and oxidative stress in human fibroblast cultures exposed to serum from septic patients. Life Sci 2012;91(7-8):237-43.

7. Barja G. Updating the mitochondrial free radical theory of aging: an integrated view, key aspects, and confounding concepts. Antioxid Redox Signal 2013;19(12):1420-45.
8. Hong SH, Kwak JH, Paik JK, et al. Association of polymorphisms in FADS gene with age-related changes in serum phospholipid polyunsaturated fatty acids and oxidative stress markers in middle-aged nonobese men. Clin Interv Aging 2013;8:585-96.

9. Liguori I, Russo G, Curcio F, et al. Oxidative stress, aging, and diseases. Clin Interv Aging 2018;13:757-72.

10. Cervantes Gracia K, Llanas-Cornejo D, Husi H. CVD and Oxidative Stress. J Clin Med 2017;6(2).

11. Higdon JV, Frei B. Obesity and oxidative stress: a direct link to CVD? Arterioscler Thromb Vasc Biol 2003;23(3): 365-7.

12. Yang Y, Sharma R, Sharma A, et al. Lipid peroxidation and cell cycle signaling: 4-hydroxynonenal, a key molecule in stress mediated signaling. Acta Biochim Pol 2003;50(2): 319-36.

13. Sharma A, Patrick B, Li J, et al. Glutathione S-transferases as antioxidant enzymes: small cell lung cancer (H69) cells transfected with hGSTA1 resist doxorubicin-induced apoptosis. Arch Biochem Biophys 2006;452(2):165-73.

14. Awasthi S, Singhal SS, Yadav S, etal.A central role of RLIP76 in regulation of glycemic control. Diabetes 2010;59(3): 714-25.

15. Zimniak $P$. What is the proximal cause of aging? Front Genet 2012;3:189.

16. Zimniak P. Relationship of electrophilic stress to aging. Free Radic Biol Med 2011;51(6):1087-105.

17. Zimniak P. 4-Hydroxynonenal and fat storage: A paradoxical pro-obesity mechanism? Cell Cycle 2010;9(17): 3393-4.

18. McKee T, McKee JR. Biochemistry: The molecular basis of life: Oxford University Press; 2015.

19. Nelson DL, Cox MM, Lehninger AL. Lehninger principles of biochemistry: W.H. Freeman; 2004.

20. Prasad S, Gupta SC, Tyagi AK. Reactive oxygen species (ROS) and cancer: Role of antioxidative nutraceuticals. Cancer Lett 2017;387:95-105.

21. Sakanyan V. Reactive chemicals and electrophilic stress in cancer: A minireview. High Throughput 2018;7(2):12.

22. Octavia Y, Tocchetti CG, Gabrielson KL, et al. Doxorubicininduced cardiomyopathy: from molecular mechanisms to therapeutic strategies. J Mol Cell Cardiol 2012;52(6): 1213-25.

23. Helmreich E. The biochemistry of cell signaling. Oxford: Oxford University Press; 2001.

24. Armstrong D, Stratton RD. Oxidative stress and antioxidant protection: The science of free radical biology and disease: Wiley; 2016.

25. Dormandy TL. Free-radical reaction in biological systems. Ann R Coll Surg Engl 1980;62(3):188-94. 
26. Anastassopoulou J. Free radicals in biological systems. Properties and chemistry of biomolecular systems Dordrecht: Springer Netherlands 1994.

27. Birben E, Sahiner UM, Sackesen C, et al. Oxidative stress and antioxidant defense. World Allergy Organ J 2012;5(1): 9-19.

28. Quan H, Galbraith PD, Norris CM, et al. Opinions on chelation therapy in patients undergoing coronary angiography: cross-sectional survey. Can J Cardiol 2007;23(8): 635-40.

29. Lu JM, Lin PH, Yao Q, et al. Chemical and molecular mechanisms of antioxidants: experimental approaches and model systems. J Cell Mol Med 2010;14(4):840-60.

30. Lobo V, Patil A, Phatak A, et al. Free radicals, antioxidants and functional foods: Impact on human health. Pharmacogn Rev 2010;4(8):118-26.

31. Mathur P, Ding Z, Saldeen T, et al. Tocopherols in the prevention and treatment of atherosclerosis and related cardiovascular disease. Clin Cardiol 2015;38(9):570-6.

32. Kammeyer A, Luiten RM. Oxidation events and skin aging. Ageing Res Rev 2015;21:16-29.

33. Forman HJ, Davies KJ, Ursini F. How do nutritional antioxidants really work: nucleophilic tone and para-hormesis versus free radical scavenging in vivo. Free Radic Biol Med 2014;66(0):24-35.

34. Park LK, Friso S, Choi SW. Nutritional influences on epigenetics and age-related disease. Proc Nutr Soc 2012;71(1): 75-83.

35. Manzanares W, Dhaliwal R, Jiang $X$, et al. Antioxidant micronutrients in the critically ill: a systematic review and meta-analysis. Critical Care 2012;16(2):R66.

36. Marik PE, Khangoora V, Rivera R, et al. Hydrocortisone, vitamin $\mathrm{C}$, and thiamine for the treatment of severe sepsis and septic shock: A retrospective before-after study. Chest 2017;151(6):1229-38.

37. Carr A, Frei B. Does vitamin $C$ act as a pro-oxidant under physiological conditions? FASEB J 1999;13(9):1007-24.

38. Naidu SD, Suzuki T, Yamamoto $M$, et al. Phenethyl isothiocyanate, a dual activator of transcription factors NRF2 and HSF1. Mol Nutr Food Res 2018;62(18):e1700908.

39. Shen $T$, Jiang $T$, Long $M$, et al. A curcumin derivative that inhibits vinyl carbamate-induced lung carcinogenesis via activation of the Nrf2 protective response. Antioxid Redox Signal 2015;23(8):651-64.

40. Sadowska-Bartosz I, Bartosz G. Effect of antioxidants supplementation on aging and longevity. Biomed Res Int 2014;2014:404680.

41. Biswas S, Hwang JW, Kirkham PA, Rahman I. Pharmacological and dietary antioxidant therapies for chronic obstructive pulmonary disease. Current medicinal chemistry. 2013;20(12):1496-530.

42. Ho E, Beaver LM, Williams DE, et al. Dietary factors and epigenetic regulation for prostate cancer prevention. Adv Nutr 2011;2(6):497-510.

43. Zhou Y, Zheng J, Li Y, et al. Natural polyphenols for prevention and treatment of cancer. Nutrients 2016;8(8): 515.

44. Laughton MJ, Halliwell B, Evans PJ, et al. Antioxidant and pro-oxidant actions of the plant phenolics quercetin, gossypol and myricetin. Effects on lipid peroxidation, hydroxyl radical generation and bleomycin-dependent damage to DNA. Biochem Pharmacol 1989;38(17):2859-65.

45. Goodyear-Bruch C, Pierce JD. Oxidative stress in critically ill patients. Am J Crit Care 2002;11(6):543-51.

46. Oldham KM, Bowen PE. Oxidative stress in critical care: Is antioxidant supplementation beneficial? J Am Diet Assoc 1998;98(9):1001-8.

47. Crimi E, Sica V, Williams-Ignarro S, et al. The role of oxidative stress in adult critical care. Free Radic Biol Med 2006;40(3):398-406.

48. Alonso de Vega JM, Diaz J, Serrano E, et al. Oxidative stress in critically ill patients with systemic inflammatory response syndrome. Crit Care Med 2002;30(8):1782-6.

49. Goode HF, Cowley HC, Walker BE, Howdle PD, Webster NR. Decreased antioxidant status and increased lipid peroxidation in patients with septic shock and secondary organ dysfunction. Crit Care Med 1995;23(4):646-51.

50. Nathens AB, Neff MJ, Jurkovich GJ, et al. Randomized, prospective trial of antioxidant supplementation in critically ill surgical patients. Ann Surg 2002;236(6):814-22.

51. Abiles J, de la Cruz AP, Castano J, et al. Oxidative stress is increased in critically ill patients according to antioxidant vitamins intake, independent of severity: a cohort study. Critical Care 2006;10(5): R146.

52. Gaustad JV, Simonsen TG, Andersen LM, et al. The effect of sunitinib treatment in human melanoma xenografts: Associations with angiogenic profiles. Transl Oncol 2017;10(2): 158-67.

53. Borrelli E, Roux-Lombard $P$, Grau GE, et al. Plasma concentrations of cytokines, their soluble receptors, and antioxidant vitamins can predict the development of multiple organ failure in patients at risk. Crit Care Med 1996;24(3): 392-7.

54. Roth E, Manhart N, Wessner B. Assessing the antioxidative status in critically ill patients. Curr Opin Clin Nutr Metab Care 2004;7(2):161-8.

55. Gutteridge JM, Mitchell J. Redox imbalance in the critically ill. Br Med Bull 1999;55(1):49-75. 
56. Motoyama T, Okamoto K, Kukita I, et al. Possible role of increased oxidant stress in multiple organ failure after systemic inflammatory response syndrome. Crit Care Med 2003;31(4):1048-52.

57. Schorah CJ, Downing C, Piripitsi A, et al. Total vitamin $\mathrm{C}$, ascorbic acid, and dehydroascorbic acid concentrations in plasma of critically ill patients. Am J Clin Nutr 1996;63(5):760-5.

58. Metnitz $P G$, Bartens $C$, Fischer $M$, et al. Antioxidant status in patients with acute respiratory distress syndrome. Intensive Care Med 1999;25(2):180-5.

59. Bunnell E, Pacht ER. Oxidized glutathione is increased in the alveolar fluid of patients with the adult respiratory distress syndrome. Am Rev Respir Dis 1993;148(5): 1174-8.

60. Richard C, Lemonnier F, Thibault M, et al. Vitamin E deficiency and lipoperoxidation during adult respiratory distress syndrome. Crit Care Med 1990;18(1):4-9.

61. Bertrand Y, Pincemail J, Hanique G, et al. Differences in tocopherol-lipid ratios in ARDS and non-ARDS patients. Intensive Care Med 1989;15(2):87-93.

62. Blackwell TS, Blackwell TR, Holden EP, et al. In vivo antioxidant treatment suppresses nuclear factor-kappa B activation and neutrophilic lung inflammation. J Immunol 1996;157(4):1630-7.

63. Schwartz MD, Moore EE, Moore FA, et al. Nuclear factorkappa $\mathrm{B}$ is activated in alveolar macrophages from patients with acute respiratory distress syndrome. Crit Care Med 1996;24(8):1285-92.

64. Spapen HD, Diltoer MW, Nguyen DN, et al. Effects of Nacetylcysteine on microalbuminuria and organ failure in acute severe sepsis: results of a pilot study. Chest 2005; 127(4):1413-9.

65. Rank N, Michel C, Haertel C, et al. N-acetylcysteine increases liver blood flow and improves liver function in septic shock patients: results of a prospective, randomized, double-blind study. Crit Care Med 2000;28(12): 3799-807.

66. Heller AR, Groth G, Heller SC, et al. N-acetylcysteine reduces respiratory burst but augments neutrophil phagocytosis in intensive care unit patients. Crit Care Med 2001; 29(2):272-6.

67. Aruoma OI, Halliwell B, Hoey BM, et al. The antioxidant action of $\mathrm{N}$-acetylcysteine: its reaction with hydrogen peroxide, hydroxyl radical, superoxide, and hypochlorous acid. Free Radic Biol Med 1989;6(6):593-7.

68. Meydani SN, Wu D, Santos MS, et al. Antioxidants and immune response in aged persons: overview of present evidence. Am J Clin Nutr 1995;62(6 Suppl):1462S-76S.
69. Gomez H, Ince C, De Backer D, et al. A unified theory of sepsis-induced acute kidney injury: inflammation, microcirculatory dysfunction, bioenergetics, and the tubular cell adaptation to injury. Shock 2014;41(1):3-11.

70. McClung JM, Kavazis AN, Whidden MA, et al. Antioxidant administration attenuates mechanical ventilationinduced rat diaphragm muscle atrophy independent of protein kinase B (PKB Akt) signalling. J Physiol 2007; 585(Pt 1):203-15.

71. Levine S, Nguyen T, Taylor N, et al. Rapid disuse atrophy of diaphragm fibers in mechanically ventilated humans. $\mathrm{N}$ Engl J Med 2008;358(13):1327-35.

72. Kavazis AN, Talbert EE, Smuder AJ, et al. Mechanical ventilation induces diaphragmatic mitochondrial dysfunction and increased oxidant production. Free Radic Biol Med 2009;46(6):842-50.

73. Mozaffarian D, Benjamin EJ, Go AS, et al. Heart disease and stroke statistics-2016 update: A report from the American Heart Association. Circulation 2016;133(4): e38-360.

74. Mannan H, Stevenson C, Peeters A, et al. Framingham risk prediction equations for incidence of cardiovascular disease using detailed measures for smoking. Heart Int 2010;5(2): e11.

75. Keaney JF, Larson MG, Vasan RS, et al. Obesity and systemic oxidative stress: clinical correlates of oxidative stress in the Framingham Study. Arterioscler Thromb Vasc Biol 2003;23(3):434-9.

76. Harris T, Cook EF, Garrison R, et al. Body mass index and mortality among nonsmoking older persons. The Framingham heart study. JAMA 1988;259(10):1520-4.

77. Patel SS, Truong U, King M, et al. Obese adolescents with polycystic ovarian syndrome have elevated cardiovascular disease risk markers. Vasc Med 2017;22(2):85-95.

78. Erhardt L. Cigarette smoking: an undertreated risk factor for cardiovascular disease. Atherosclerosis 2009;205(1):23-32.

79. Jugdutt BI, editor. Aging and Heart Failure: Mechanisms and Management. New York: Springer; 2014.

80. Strait JB, Lakatta EG. Aging-associated cardiovascular changes and their relationship to heart failure. Heart Fail Clin 2012;8(1):143-64.

81. Yabluchanskiy A, Ma Y, Chiao YA, et al. Cardiac aging is initiated by matrix metalloproteinase-9-mediated endothelial dysfunction. Am J Physiol Heart Circ Physiol 2014; 306(10):H1398-407.

82. Mitra S, Goyal T, Mehta JL. Oxidized LDL, LOX-1 and atherosclerosis. Cardiovasc Drugs Ther 2011;25(5):419-29.

83. Lu J, Mitra S, Wang X, et al. Oxidative stress and lectin-like ox-LDL-receptor LOX-1 in atherogenesis and tumorigenesis. Antioxid Redox Signal 2011;15(8):2301-33. 
84. Singla $\mathrm{S}, \mathrm{Hu} \mathrm{C}$, Mizeracki A, et al. Decorin in atherosclerosis. Ther Adv Cardiovasc Dis 2011;5(6):305-14.

85. Giugliano D, Ceriello A, Paolisso G. Oxidative stress and diabetic vascular complications. Diabetes Care 1996;19(3): 257-67.

86. Sims CR, Singh SP, Mu S, et al. Rolipram improves outcome in a rat model of infant sepsis-induced cardiorenal syndrome. Front Pharmacol 2017;8(237):237.

87. Wang H, Chen X, Su Y, et al. p47(phox) contributes to albuminuria and kidney fibrosis in mice. Kidney Int 2015; 87(5):948-62.

88. Sureshbabu A, Ryter SW, Choi ME. Oxidative stress and autophagy: crucial modulators of kidney injury. Redox Biol 2015;4:208-14.

89. Marine A, Krager KJ, Aykin-Burns N, et al. Peroxynitrite induced mitochondrial biogenesis following MnSOD knockdown in normal rat kidney (NRK) cells. Redox Biol 2014;2:348-57.

90. Kalyanaraman B. Teaching the basics of redox biology to medical and graduate students: Oxidants, antioxidants and disease mechanisms. Redox Biol 2013;1(1):244-57.

91. Salvadori M, Rosso G, Bertoni E. Update on ischemiareperfusion injury in kidney transplantation: Pathogenesis and treatment. World J Transplant 2015;5(2):52-67.

92. Kaushal GP, Kaushal V, Hong X, et al. Role and regulation of activation of caspases in cisplatin-induced injury to renal tubular epithelial cells. Kidney Int 2001;60(5):1726-36.

93. Gill R, Tsung A, Billiar T. Linking oxidative stress to inflammation: Toll-like receptors. Free Radic Biol Med 2010; 48(9):1121-32.

94. Rosin DL, Okusa MD. Dangers within: DAMP responses to damage and cell death in kidney disease. J Am Soc Nephrol 2011;22(3):416-25.

95. Smathers RL, Galligan JJ, Stewart BJ, et al. Overview of lipid peroxidation products and hepatic protein modification in alcoholic liver disease. Chem Biol Interact 2011; 192(1-2):107-12.

96. Tomita K, Tamiya G, Ando S, et al. AICAR, an AMPK activator, has protective effects on alcohol-induced fatty liver in rats. Alcohol Clin Exp Res 2005;29(12 Suppl):240S-5S.

97. Bose C, Awasthi S, Sharma R, et al. Sulforaphane potentiates anticancer effects of doxorubicin and attenuates its cardiotoxicity in a breast cancer model. PloS One 2018;13(3): e0193918.

98. Singh P, Sharma R, McElhanon K, et al. Sulforaphane protects the heart from doxorubicin-induced toxicity. Free Radic Biol Med 2015;86:90-101.

99. D’Archivio M, Scazzocchio B, Filesi C, et al. Oxidised LDL up-regulate CD36 expression by the Nrf2 pathway in 3T3-L1 preadipocytes. FEBS Lett 2008;582(15):2291-8.
100. Ishii $\mathrm{T}$, Itoh $\mathrm{K}$, Ruiz $\mathrm{E}$, et al. Role of $\mathrm{Nrf} 2$ in the regulation of CD36 and stress protein expression in murine macrophages: activation by oxidatively modified LDL and 4-hydroxynonenal. Circ Res 2004;94(5):609-16.

101. Zhou R, Lin J, Wu D. Sulforaphane induces Nrf2 and protects against CYP2E1-dependent binge alcohol-induced liver steatosis. Biochim Biophys Acta 2014;1840(1):209-18.

102. $\mathrm{Wu} \mathrm{KC}$, Liu J, Klaassen $\mathrm{CD}$. Role of $\mathrm{Nrf} 2$ in preventing ethanol-induced oxidative stress and lipid accumulation. Toxicol Appl Pharmacol 2012;262(3):321-9.

103. Rodriguez-Rodriguez A, Egea-Guerrero JJ, MurilloCabezas F, et al. Oxidative stress in traumatic brain injury. Curr Med Chem 2014;21(10):1201-11.

104. Talha S, Bouitbir J, Charles AL, et al. Pretreatment with brain natriuretic peptide reduces skeletal muscle mitochondrial dysfunction and oxidative stress after ischemiareperfusion. J Appl Physiol 2013;114(2):172-9.

105. Singhal SS, Singh SP, Singhal $P$, et al. Antioxidant role of glutathione S-transferases: 4-Hydroxynonenal, a key molecule in stress-mediated signaling. Toxicol Appl Pharmacol 2015;289(3):361-70.

106. Chen G, Waxman DJ. Role of cellular glutathione and glutathione S-transferase in the expression of alkylating agent cytotoxicity in human breast cancer cells. Biochem Pharmacol 1994;47(6):1079-87.

107. Awasthi S, Srivastava SK, Ahmad F, et al. Interactions of glutathione S-transferase-pi with ethacrynic acid and its glutathione conjugate. Biochim Biophys Acta 1993;1164(2): 173-8.

108. Bernard GR, Wheeler AP, Arons MM, et al. A trial of antioxidants $\mathrm{N}$-acetylcysteine and procysteine in ARDS. The antioxidant in ARDS study group. Chest 1997;112(1): 164-72.

109. Ortolani O, Conti A, De Gaudio AR, et al. Protective effects of $\mathrm{N}$-acetylcysteine and rutin on the lipid peroxidation of the lung epithelium during the adult respiratory distress syndrome. Shock 2000;13(1):14-8.

110. Laurent $T$, Markert M, Feihl F, et al. Oxidant-antioxidant balance in granulocytes during ARDS. Effect of N-acetylcysteine. Chest 1996;109(1):163-6.

111. Gadek JE, DeMichele SJ, Karlstad MD, et al. Effect of enteral feeding with eicosapentaenoic acid, gammalinolenic acid, and antioxidants in patients with acute respiratory distress syndrome. Enteral nutrition in ARDS study group. Crit Care Med 1999;27(8):1409-20.

112. Galley HF, Howdle PD, Walker BE, et al. The effects of intravenous antioxidants in patients with septic shock. Free Radic Biol Med 1997;23(5):768-74.

113. Angstwurm MW, Schottdorf J, Schopohl J, et al. Selenium replacement in patients with severe systemic inflammatory 
response syndrome improves clinical outcome. Crit Care Med 1999;27(9):1807-13.

114. Heyland D, Muscedere J, Wischmeyer PE, et al. A randomized trial of glutamine and antioxidants in critically ill patients. N Engl J Med 2013;368(16):1489-97.

115. Manzanares W, Lemieux M, Elke G, et al. High-dose intravenous selenium does not improve clinical outcomes in the critically ill: a systematic review and meta-analysis. Crit Care 2016;20(1):356.

116. Langlois PL, Hardy G, Manzanares W. Pharmaconutrition with intravenous selenium in intensive care: The end of an era? Nutrition 2018;45:142-4.

117. Shishehbor MH, Hazen SL. Inflammatory and oxidative markers in atherosclerosis: relationship to outcome. Curr Atheroscler Rep 2004;6(3):243-50.

118. Davignon J, Jacob RF, Mason RP. The antioxidant effects of statins. Coron Artery Dis 2004;15(5):251-8.

119. Moon GJ, Kim SJ, Cho YH, et al. Antioxidant effects of statins in patients with atherosclerotic cerebrovascular disease. J Clin Neurol 2014;10(2):140-7.

120. Chopra M, Beswick H, Clapperton M, et al. Antioxidant effects of angiotensin-converting enzyme (ACE) inhibitors: free radical and oxidant scavenging are sulfhydryl dependent, but lipid peroxidation is inhibited by both sulfhydryland nonsulfhydryl-containing ACE inhibitors. J Cardiovasc Pharmacol 1992;19(3):330-40.

121. Wen H, Gwathmey JK, Xie LH. Oxidative stressmediated effects of angiotensin II in the cardiovascular system. World J Hypertens 2012;2(4):34-44.

122. Ceron CS, Castro MM, Rizzi E, et al. Spironolactone and hydrochlorothiazide exert antioxidant effects and reduce vascular matrix metalloproteinase- 2 activity and expression in a model of renovascular hypertension. Br J Pharmacol 2010;160(1):77-87.

123. Miura T, Muraoka S, Ogiso T. Antioxidant activity of adrenergic agents derived from catechol. Biochem Pharmacol 1998;55(12):2001-6.

124. Susanna Mak, Newton GE. Vitamin C augments the inotropic response to dobutamine in humans with normal left ventricular function. Circulation 2000;103:826-30.

125. Farkhutdinov U, Farkhutdinov S, Yakupova G, et al. The mechanisms of anti- inflammatory action of bronchodilators. Eur Respir J 2013;42(Suppl 57).

126. Zwicker K, Damerau W, Dikalov S, et al. Superoxide radical scavenging by phenolic bronchodilators under aprotic and aqueous conditions. Biochem Pharmacol 1998;56(3): 301-5.

127. Grant D, Long WF, Mackintosh G, et al. The antioxidant activity of heparins. Biochem Soc Trans 1996;24(2): 194S.
128. Albertini R, Rindi S, Passi A, et al. Heparin protection against $\mathrm{Fe} 2+-$ and $\mathrm{Cu} 2+-$ mediated oxidation of liposomes. FEBS Lett 1996;383(3):155-8.

129. Vellinga NA, Veenstra G, Scorcella C, et al. Effects of ketanserin on microcirculatory alterations in septic shock: An open-label pilot study. J Crit Care 2015;30(6):1156-62.

130. Liu $C$, Zhang $X$, Zhou JX, et al. The protective action of ketanserin against lipopolysaccharide-induced shock in mice is mediated by inhibiting inducible NO synthase expression via the MEK/ERK pathway. Free Radic Biol Med 2013;65:658-66.

131. Liu C, Zhang GF, Song SW, et al. Effects of ketanserin on endotoxic shock and baroreflex function in rodents. J Infect Dis 2011;204(10):1605-12.

132. Cazzola M, Guidetti E, Sepe J, et al. Acute respiratory and cardiovascular effects of inhaled ketanserin in chronic obstructive pulmonary disease. A comparative study with intravenously administered ketanserin. Chest 1990;97(4): 901-5.

133. Cazzola M, D’Amato G, Lobefalo G, et al. Ketanserin, a new blocking agent of serotonin S2-receptors. Respiratory functional effects in chronic obstruction of the airways. Chest 1987;92(5):863-6.

134. Venkataramanujam S, Mahaneem M, Hisanori K. Melatonin in bacterial and viral infections with focus on sepsis: A review. Recent Pat Endocr Metab Immune Drug Discov 2012;6(1):30-9.

135. Srinivasan V, Pandi-Perumal SR, Spence DW, et al. Melatonin in septic shock: some recent concepts. J Crit Care 2010;25(4):656 e1-6.

136. Wu JY, Tsou MY, Chen $\mathrm{TH}$, et al. Therapeutic effects of melatonin on peritonitis-induced septic shock with multiple organ dysfunction syndrome in rats. J Pineal Res 2008; 45(1):106-16.

137. D'Amato LA, Mistraletti G, Longhi D, et al. Melatonin blood values and total antioxidant capacity in critically ill patients. Critical Care 2014;18(1): P436.

138. Alamili $M$, Bendtzen $K$, Lykkesfeldt $J$, et al. Melatonin suppresses markers of inflammation and oxidative damage in a human daytime endotoxemia model. J Crit Care 2014;29(1):184 e9-e13.

139. Kelso GF, Porteous CM, Coulter CV, et al. Selective targeting of a redox-active ubiquinone to mitochondria within cells: antioxidant and antiapoptotic properties. J Biol Chem 2001;276(7):4588-96.

140. Dhanasekaran A, Kotamraju S, Kalivendi SV, et al. Supplementation of endothelial cells with mitochondriatargeted antioxidants inhibit peroxide-induced mitochondrial iron uptake, oxidative damage, and apoptosis. J Biol Chem 2004;279(36):37575-87. 
141. Lowes DA, Thottakam BM, Webster NR, et al. The mitochondria-targeted antioxidant MitoQ protects against organ damage in a lipopolysaccharide-peptidoglycan model of sepsis. Free Radic Biol Med 2008;45(11):1559-65.

142. Bolner A, Micciolo R, Bosello O, et al. A panel of oxidative stress markers in Parkinson's disease. Clin Lab 2016; 62(1-2):105-12.

143. Ho E, Karimi Galougahi $\mathrm{K}$, Liu $\mathrm{CC}$, et al. Biological markers of oxidative stress: Applications to cardiovascular research and practice. Redox Biol 2013;1(1):483-91.

144. Lin D, Saleh S, Liebler DC. Reversibility of covalent electrophile-protein adducts and chemical toxicity. Chem Res Toxicol 2008;21(12):2361-9.

145. Blair IA. Analysis of endogenous glutathione-adducts and their metabolites. Biomed Chromatogr 2010;24(1):29-38.

146. Moss EJ, Neal GE, Judah DJ. The mercapturic acid pathway metabolites of a glutathione conjugate of aflatoxin B1. Chem Biol Interact 1985;55(1-2):139-55.

147. Pajaud J, Kumar S, Rauch C, et al. Regulation of signal transduction by glutathione transferases. Int $\mathrm{J}$ Hepatol 2012;2012:137676.

148. Scarbrough PM, Mapuskar KA, Mattson DM, et al. Simultaneous inhibition of glutathione- and thioredoxin-dependent metabolism is necessary to potentiate 17AAG- induced cancer cell killing via oxidative stress. Free Radic Biol Med 2012;52(2):436-43.

149. Liang A, Wang Y, Woodard LE, et al. Loss of glutathione S-transferase A4 accelerates obstruction-induced tubule damage and renal fibrosis. J Pathol 2012;228(4):448-58.

150. Singhal J, Nagaprashantha L, Vatsyayan R, et al. RLIP76, a glutathione- conjugate transporter, plays a major role in the pathogenesis of metabolic syndrome. PloS One 2011;6(9): e24688.

151. Rosse C, L'Hoste S, Offner N, et al. RLIP, an effector of the Ral GTPases, is a platform for Cdk1 to phosphorylate epsin during the switch off of endocytosis in mitosis. J Biol Chem 2003;278(33):30597-604.

152. Awasthi S, Singhal SS, Sharma R, et al. Transport of glutathione conjugates and chemotherapeutic drugs by RLIP76 (RALBP1): a novel link between G-protein and tyrosine kinase signaling and drug resistance. Int J Cancer 2003;106(5):635-46.

153. Awasthi S, Cheng JZ, Singhal SS, et al. Functional reassembly of ATP-dependent xenobiotic transport by the N- and C-terminal domains of RLIP76 and identification of ATP binding sequences. Biochemistry 2001;40(13):4159-68.

154. Awasthi S, Cheng J, Singhal SS, et al. Novel function of human RLIP76: ATP-dependent transport of glutathione conjugates and doxorubicin. Biochemistry 2000;39(31): 9327-34.
155. Singhal SS, Sehrawat A, Mehta A, et al. Functional reconstitution of RLIP76 catalyzing ATP-dependent transport of glutathione-conjugates. Int J Oncol 1992.

156. Singhal SS, Nagaprashantha L, Singhal P, et al. RLIP76 inhibition: A promising developmental therapy for neuroblastoma. Pharm Res 2017;34(8):1673-82.

157. Singhal SS, Wickramarachchi D, Yadav S, et al. Glutathione-conjugate transport by RLIP76 is required for clathrin-dependent endocytosis and chemical carcinogenesis. Mol Cancer Ther 2011;10(1):16-28.

158. Sahu M, Sharma R, Yadav $S$, et al. Lens specific RLIP76 transgenic mice show a phenotype similar to microphthalmia. Exp Eye Res 2014;118:125-34.

159. Singhal SS, Figarola J, Singhal J, et al. RLIP76 protein knockdown attenuates obesity due to a high-fat diet. J Biol Chem. 2013;288(32):23394-406.

160. Lee S, Wurtzel JG, Singhal SS, et al. RALBP1/RLIP76 depletion in mice suppresses tumor growth by inhibiting tumor neovascularization. Cancer Res 2012;72(20): 5165-73.

161. Singhal SS, Singhal J, Yadav S, et al. RLIP76: a target for kidney cancer therapy. Cancer Res. 2009;69(10):4244-51.

162. Singhal J, Singhal SS, Yadav S, et al. RLIP76 in defense of radiation poisoning. Int J Radiat Oncol Biol Phys 2008; 72(2):553-61.

163. Figarola JL, Singhal $P$, Rahbar $S$, et al. COH-SR4 reduces body weight, improves glycemic control and prevents hepatic steatosis in high fat diet-induced obese mice. PloS One 2013;8(12): e83801.

164. Awasthi S, Tompkins J, Singhal J, et al. Rlip depletion prevents spontaneous neoplasia in TP53 null mice. Proc Natl Acad Sci USA 2018;115(15):3918-23.

165. Singhal J, Yadav S, Nagaprashantha LD, et al. Targeting p53-null neuroblastomas through RLIP76. Cancer Prev Res (Phila) 2011;4(6):879-89.

166. Singhal SS, Singhal J, Yadav S, et al. Regression of lung and colon cancer xenografts by depleting or inhibiting RLIP76 (Ral-binding protein 1). Cancer Res 2007;67(9):4382-9.

167. Singhal SS, Awasthi YC, Awasthi S. Regression of melanoma in a murine model by RLIP76 depletion. Cancer Res 2006;66(4):2354-60.

168. Awasthi YC, Sharma R, Cheng JZ, et al. Role of 4-hydroxynonenal in stress-mediated apoptosis signaling. Mol Aspects Med 2003;24(4-5):219-30.

169. Hu Y, Mivechi NF. HSF-1 interacts with Ral-binding protein 1 in a stress-responsive, multiprotein complex with HSP90 in vivo. J Biol Chem 2003;278(19):17299-306.

170. Cantor SB, Urano T, Feig LA. Identification and characterization of Ral-binding protein 1, a potential downstream target of Ral GTPases. Mol Cell Biol 1995;15(8):4578-84. 
171. Jullien-Flores V, Dorseuil O, Romero F, et al. Bridging Ral GTPase to Rho pathways. RLIP76, a Ral effector with CDC42/Rac GTPase-activating protein activity. J Biol Chem 1995;270(38):22473-7.

172. Kashatus DF, Lim KH, Brady DC, et al. RALA and RALBP1 regulate mitochondrial fission at mitosis. Nat Cell Biol 2011;13(9):1108-15.

173. Moskalenko S, Henry DO, Rosse C, et al. The exocyst is a Ral effector complex. Nat Cell Biol 2002;4(1):66-72.

174. Park SH, Weinberg RA. A putative effector of Ral has homology to Rho/Rac GTPase activating proteins. Oncogene 1995;11(11):2349-55.

175. Morimoto RI. Regulation of the heat shock transcriptional response: cross talk between a family of heat shock factors, molecular chaperones, and negative regulators. Genes Dev 1998;12(24):3788-96.

176. Jullien-Flores V, Mahe Y, Mirey G, et al. RLIP76, an effector of the GTPase Ral, interacts with the AP2 complex: involvement of the Ral pathway in receptor endocytosis. J Cell Sci 2000;113 (Pt 16):2837-44.

177. Morinaka K, Koyama S, Nakashima S, et al. Epsin binds to the EH domain of POB1 and regulates receptor-mediated endocytosis. Oncogene 1999;18(43):5915-22.

178. Nakashima S, Morinaka K, Koyama S, et al. Small G protein Ral and its downstream molecules regulate endocytosis of EGF and insulin receptors. EMBO J 1999;18(13):3629-42.

179. Tazat K, Harsat M, Goldshmid-Shagal A, et al. Dual effects of Ral-activated pathways on p27 localization and TGFbeta signaling. Mol Biol Cell 2013;24(11):1812-24.

180. Awasthi S, Singhal SS, Pikula S, et al. ATP-Dependent human erythrocyte glutathione-conjugate transporter. II. Functional reconstitution of transport activity. Biochemistry 1998;37(15):5239-48.

181. Awasthi S, Sharma R, Yang Y, et al. Transport functions and physiological significance of $76 \mathrm{kDa}$ Ral-binding GTPase activating protein (RLIP76). Acta Biochim Pol 2002;49(4):855-67.

182. Awasthi S, Singhal SS, Srivastava Sked, et al. ATP-Dependent human erythrocyte glutathione-conjugate transporter. I. Purification, photoaffinity labeling, and kinetic characteristics of ATPase activity. Biochemistry 1998;37(15):5231-8.

183. Awasthi S, Sharma R, Singhal SS, et al. Modulation of cisplatin cytotoxicity by sulphasalazine. Br J Cancer 1994;70(2):190-4.

184. Awasthi YC, Sharma R, Singhal SS. Human glutathione S-transferases. Int J Biochem 1994;26(3):295-308.

185. Sharma R, Singhal SS, Wickramarachchi D, et al. RLIP76 (RALBP1)-mediated transport of leukotriene C4 (LTC4) in cancer cells: implications in drug resistance. Int J Cancer 2004;112(6):934-42.

186. Nagaprashantha L, Vartak $N$, Awasthi $S$, et al. Novel anticancer compounds for developing combinatorial therapies to target anoikis-resistant tumors. Pharm Res 2012;29(3): 621-36.

187. Awasthi S, Singhal SS, Awasthi YC, et al. RLIP76 and cancer. Clin Cancer Res 2008;14(14):4372-7.

188. Stuckler D, Singhal J, Singhal SS, et al. RLIP76 transports vinorelbine and mediates drug resistance in non-small cell lung cancer. Cancer Res 2005;65(3):991-8.

189. Yang Y, Sharma A, Sharma R, et al. Cells preconditioned with mild, transient UVA irradiation acquire resistance to oxidative stress and UVA-induced apoptosis: role of 4-hydroxynonenal in UVA-mediated signaling for apoptosis. J Biol Chem 2003;278(42):41380-8.

190. Chikara S, Nagaprashantha LD, Singhal J, et al. Oxidative stress and dietary phytochemicals: Role in cancer chemoprevention and treatment. Cancer Lett 2018;413: 122-34.

191. Singhal SS, Singhal J, Figarola JL, et al. 2'-Hydroxyflavanone: A promising molecule for kidney cancer prevention. Biochem Pharmacol 2015;96(3):151-8.

192. Singhal J, Chikara S, Horne D, et al. 2'-Hydroxyflavanone inhibits in vitro and in vivo growth of breast cancer cells by targeting RLIP76. Mol Carcinog 2018;57(12):1751-62.

193. Nagaprashantha LD, Singhal J, Li H, et al. 2'-Hydroxyflavanone effectively targets RLIP76-mediated drug transport and regulates critical signaling networks in breast cancer. Oncotarget 2018;9(26):18053-68.

194. Singhal J, Nagaprashantha L, Chikara S, et al. 2'-Hydroxyflavanone: A novel strategy for targeting breast cancer. Oncotarget. 2017;8(43):75025-37.

195. Tijani L, Awasthi S. PS01.34: Differential modulation of glutathione metabolism in adeno and squamous NSCLC by 2HF. J Thorac Oncol 2016;11(11S): S289-S90.

196. Wu K, Ning Z, Zhou J, et al. 2'-hydroxyflavanone inhibits prostate tumor growth through inactivation of AKT/ STAT3 signaling and induction of cell apoptosis. Oncol Rep 2014;32(1):131-8.

197. Singhal J, Nagaprashantha LD, Vatsyayan R, et al. Didymin induces apoptosis by inhibiting N-Myc and upregulating RKIP in neuroblastoma. Cancer Prev Res (Phila) 2012;5(3): 473-83.

198. Nagaprashantha LD, Vatsyayan R, Singhal J, et al. 2'hydroxyflavanone inhibits proliferation, tumor vascularization and promotes normal differentiation in VHL-mutant renal cell carcinoma. Carcinogenesis 2011;32(4):568-75. 